\title{
The Interannual Dominant Covariation Mode of Boreal Summer Monsoon Rainfall during 1979-2014
}

\author{
YUQIAN HAO \\ State Key Laboratory of Severe Weather, and Institute of Climate System, Chinese Academy of \\ Meteorological Sciences, and University of Chinese Academy of Sciences, Beijing, China \\ Boqi LiU, Congwen ZHU, AND SHuANGMEI MA \\ State Key Laboratory of Severe Weather, and Institute of Climate System, Chinese Academy of \\ Meteorological Sciences, Beijing, China
}

(Manuscript received 23 June 2017, in final form 10 February 2018)

\begin{abstract}
The boreal summer monsoon (BSM), which includes the monsoons over India (IND), the western North Pacific (WNP), East Asia (EA), North America (NAM), and North Africa (NAF), shows prominent interannual variation (IAV) in summer precipitation and affects the areas with the largest populations in the world. In the present, the EOF analysis is used to extract the BSM dominant covariation mode during 19792014. This mode is featured by the out-of-phase rainfall IAV over the WNP compared with the other BSM members. The BSM covariation mode is closely associated with the upper- and lower-level coupled circulations, which are characterized by two anomalous zonal circulations over the tropical oceans coupled near the date line and an abnormal meridional cell over the WNP and EA regions, respectively. Furthermore, the strength of this mode depends on the phase relationship of rainfall IAV between the WNP and NAM monsoon regions, which is modulated by the seasonal evolution of ENSO events and the resultant SST anomalies (SSTAs) in the tropical Indian Ocean (TIO). The weaker mode is accompanied by the in-phase rainfall IAV between these two regions, along with the persisting ENSO events and stronger SSTAs in the TIO from winter to summer. In the years with fast-decaying ENSO events and the related weaker TIO SSTA, the out-of-phase rainfall IAV between the WNP and NAM region takes place to enhance this mode. A series of AGCM sensitivity experiments could reproduce the anomalies of atmospheric circulation related to the distinct seasonal evolution of ENSO events.
\end{abstract}

\section{Introduction}

Monsoons generally feature a seasonal dry-wet swing with the reverse of prevailing wind direction between the cold and warm seasons. During boreal summer, the convection maximum is located over monsoon regions in the Northern Hemisphere, where the lower tropospheric winds flow toward heated continents away from the colder oceanic regions of the winter hemisphere. In the upper troposphere, the winds blow from the summer to the winter hemisphere (Webster and Fasullo 2003; Boos and Hurley 2013). Except for its pronounced seasonal variation, the interannual variability (IAV) of the summer monsoon can modulate the global transport of atmospheric energy and water vapor, causing the

Corresponding author: Dr. Boqi Liu, liubq@cma.gov.cn droughts and flood-related extreme climate events over areas to influence two-thirds of the world population's daily lives (An et al. 2015). Hence, the IAV of summer monsoon is always the focus of monsoon studies, and monsoon prediction is among the most challenging problems in climate science.

Many previous studies have addressed the IAV of regional boreal summer monsoon (BSM) in the Northern Hemisphere that is most outstanding over the world, especially about its relationship with El Niño-Southern Oscillation (ENSO), whose IAV is strongest for the airsea interaction in tropics. In the Eastern Hemisphere, most population suffers the flood and drought disaster induced by the IAV of the western North Pacific (WNP), Indian (IND), and East Asian (EA) summer monsoons. The WNP convection is suppressed after El Niño events, when the warmer sea surface temperature anomalies 
(SSTAs) in the equatorial central-eastern Pacific lead to the large-scale upper-level convergence and descent anomalies over the WNP (Zhang et al. 1999; Wu and Wang 2000; Zhao et al. 2007). The IAV of the IND summer monsoon is not only altered by the ENSO events (Webster and Yang 1992; Goswami and Mohan 2001; Annamalai et al. 2010) but also modulated by the land conditions over Eurasia (Kumar et al. 1999). The situation of the EA summer monsoon (EASM) is more complex because it is located in the subtropics and influenced by both tropical and mid- to high-latitude circulations. The influencing factors of EASM include the ENSO event, the tropical Indian Ocean (TIO), the Indian summer monsoon, the winter snow cover over Eurasia and the Tibetan Plateau, and even the summer North Atlantic Oscillation (e.g., Tan et al. 1999; Wang et al. 2001; Wang et al. 2003; Ding and Chan 2005; Ding et al. 2010; Linderholm et al. 2011). In the Western Hemisphere, the major summer monsoon includes the North American (NAM) and North African (NAF) summer monsoon. The NAM summer monsoon rainfall increases off the southwestern coast of Mexico after the mature El Niño stage (Reyes and Cadet 1988; Reyes and Mejia-Trejo 1991). The IAV of NAM rainfall has been attributed to the tropical Atlantic SSTAs (Rowell et al. 1995), which are partly associated with ENSO events (Huang 2004). In addition, the IAV of NAM is also affected by the tropical and North Pacific SSTAs (Yu and Wallace 2000; Castro et al. 2001), the spring snow cover over North America (Gutzler and Preston 1997; Hawkins et al. 2002), the summertime Madden-Julian oscillation (Barlow and Salstein 2006; Lorenz and Hartmann 2006), and the tropical easterly waves (Adams and Stensrud 2007).

Some recent studies have noticed the interaction among the BSM members on interannual and even longer time scales. For instance, Wang et al. (2001) indicated that a weakened WNP summer monsoon with suppressed convection along $10^{\circ}-20^{\circ} \mathrm{N}$ is accompanied by an enhanced EA summer monsoon along the mei-yubaiu front, implicating a strong coupling between the WNP summer monsoon and EASM circulations. Lee et al. (2014) recognized the significant interrelationships among the Asian (including the IND, WNP, and EA summer monsoon), NAM, and NAF summer monsoon precipitations after 1994. Also, a teleconnection between IND and the EASM has been reported by Liu and Ding (2008). Furthermore, the NAF summer monsoon could be influenced by the low-level winds coming from the IND summer monsoon (Rodwell and Hoskins 1996; Raicich et al. 2003). In contrast, the NAM system is connected with the remote land surface conditions (Lau and Weng 2002; Koster et al. 2004) and the upper-level
Asia-North America teleconnection (Zhu and Li 2016), which is critical for the IAV of the Asian summer monsoon. Moreover, a number of studies in recent years have drawn attention to the increasing intensity of heavy rainfall events, heat waves, and severe droughts over monsoon regions. It is necessary for monsoon scientists to sharpen predictions of the start dates and intensity of monsoons and how monsoons will respond to climate change. However, changes in the regional monsoon cannot be fully understood without a climate system perspective. Therefore, more detailed studies are required to establish that how the regional monsoons are linked, which is important for the further understanding of the multiscale variation of global monsoons (e.g., Wang and Ding 2008; Lee et al. 2014).

In this regard, the present study aims to investigate the covariation of the BSM IAV and its relevant atmospheric circulation, and to examine the maintenance mechanisms for this dominant covariation mode from the aspects of both the internal dynamical process and external forcing, and in particular its association with the seasonal evolution of ENSO event after its peak phase. The remainder of this paper is organized as follows. Section 2 introduces the data and methods, including the definition of the BSM dominant covariation mode. Section 3 describes the features of atmospheric circulation associated with this mode. In section 4 , we analyze the maintenance mechanism for this mode. The influence of tropical SSTAs on this mode is examined in section 5. Finally, section 6 presents the conclusions and discussion.

\section{Data and methodology}

\section{a. Data}

The global precipitation data are extracted from the monthly Global Precipitation Climatology Project (GPCP) (Huffman et al. 1997; Adler et al. 2003) and the CPC Merged Analysis of Precipitation (CMAP) (Xie and Arkin 1997) datasets for 1979-2014, with a horizontal resolution of $2.5^{\circ} \times 2.5^{\circ}$. To reduce the data uncertainties, the arithmetic mean of the GPCP and CMAP data is used to depict the IAV of BSM rainfall (Wang et al. 2012; Hao et al. 2016). The ERA-Interim reanalysis dataset for the same period includes threedimensional wind, air temperature, and specific humidity for the 37 standard isobars, and mean surface sea level pressure (SLP), with a horizontal resolution of $1.5^{\circ} \times 1.5^{\circ}$ (Dee et al. 2011). The monthly HadSST2 sea surface temperature (SST) with a horizontal resolution of $1.0^{\circ} \times 1.0^{\circ}$ was provided by the Met Office (Rayner et al. 2006). The linear trend and climatology of each element had been removed first, and the standardized 


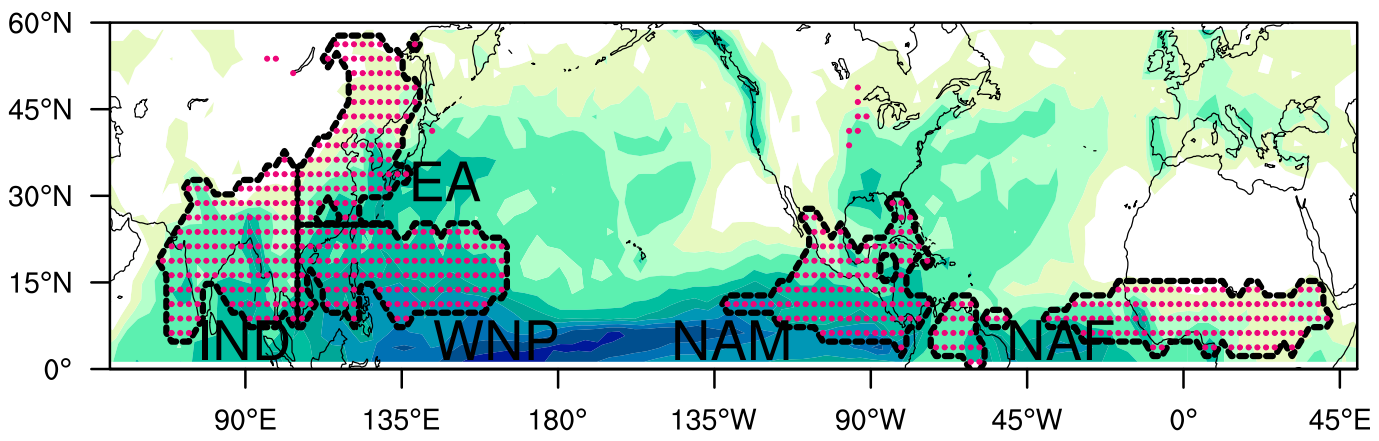

\begin{tabular}{|l|l|l|l|l|l|ll|ll|}
\hline & & & & & & & & & \\
\hline
\end{tabular}

FIG. 1. The BSM domains (red dots and black dashed frames) and the standard deviation of the BSM rainfall (shading; $\mathrm{mm} \mathrm{day}^{-1}$ ) on the interannual time scale. The BSM domain is defined as where the local summer-minuswinter precipitation rate exceeds $2.0 \mathrm{~mm} \mathrm{day}^{-1}$, and the local summer precipitation exceeds $55 \%$ of the annual total precipitation. Summer denotes May to September and winter denotes November to March in the Northern Hemisphere.

anomaly was treated as the IAV. Considering the different onset and withdrawal timing of the regional BSM monsoons, we defined the summertime as the period from May to September, which primarily covers the evolutions of rainfall over each BSM subregion, and the wintertime was defined from November to the following March.

\section{b. Description of the BSM domain}

The global monsoon (GM) domain is defined using either the monsoon precipitation (e.g., Wang 1994; Qian 2000; Zeng and Lu 2004; Wang and Ding 2006, 2008; Hsu et al. 2011) or the seasonal reversal of prevailing wind (e.g., Trenberth et al. 2000; Li and Zeng 2002, 2003), or both (e.g., Webster 1987; Zhang and Wang 2008; Qian and Tang 2010). Generally, the BSM domain identified by the different criteria is consistent, except for some minor distinctions.

Following Wang et al. (2012), here we identified the BSM domain as the region where the local summerminus-winter precipitation exceeds $2.0 \mathrm{~mm} \mathrm{day}^{-1}$ and the summer precipitation exceeds $55 \%$ of the total annual rainfall. The BSM, owning the large IAV in rainfall in the Northern Hemisphere (Fig. 1), includes the tropical monsoons over the WNP, IND, NAM, and NAF, and the subtropical summer monsoon over the EA.

\section{c. Definition of BSM dominant covariation mode}

The empirical orthogonal function (EOF) was applied to extract the covariation of the rainfall variability of each BSM member, and we treated the first leading EOF mode as the BSM dominant covariation mode, and its interannual fluctuation was described by the related principal component (PC1). Since the EOF analysis is very sensitive to the selection of spatial domain, we have conducted the EOF analysis in three distinct ways to avoid the uncertainty involved by the domain selection. In detail, we have applied the EOF analysis on the standardized summer rainfall anomalies 1) over the entire Northern Hemisphere (Figs. 2a,d) and 2) inside the BSM regions (Figs. 2b,d), and 3) the five area-averaged rainfall indices in each BSM subregion (Figs. 2c,d), respectively.

\section{d. Numerical model description}

For validating the results of data analysis, a linear baroclinic model (LBM) was used to examine the internal association among the BSM members. This LBM was an exactly linearized set of primitive equations and had been extensively used for diagnostic studies of atmospheric teleconnections (Watanabe and Kimoto 2000; Pan et al. 2006; Xie et al. 2009). We used a version of LBM with T42 resolution in the horizontal and 20 sigma levels in the vertical. In each LBM sensitivity experiment, the LBM was forced by a series of prescribed diabatic heating with specific horizontal and vertical distribution, and the climate-mean wind field during May-September was setup as the basic flow. We integrated the LBM for 30 days, and the average values in the last 15 days were treated as the stationary atmospheric response to the diabatic forcing. In addition, we used the NCAR Community Atmosphere Model version 5.1 (CAM5.1), a complete AGCM, to verify the relationship between the BSM dominant covariation mode and the SSTAs on the interannual time scale. In this study, the horizontal resolution of CAM5.1 is about 
(a) EOF1 on Northern Hemisphere


(c) EOF1 on Timeseries of BSM Pr. $\quad 39.0 \%$

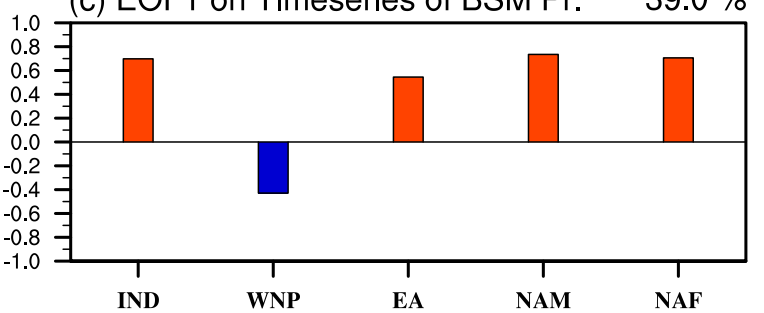

(b) EOF1 on BSM domain
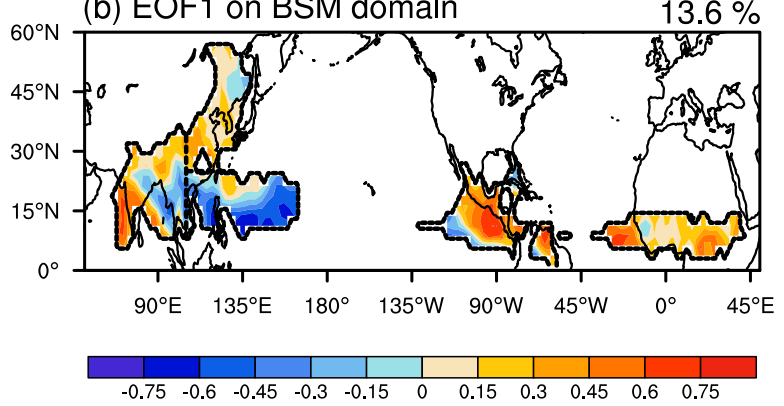

(d) PC1s

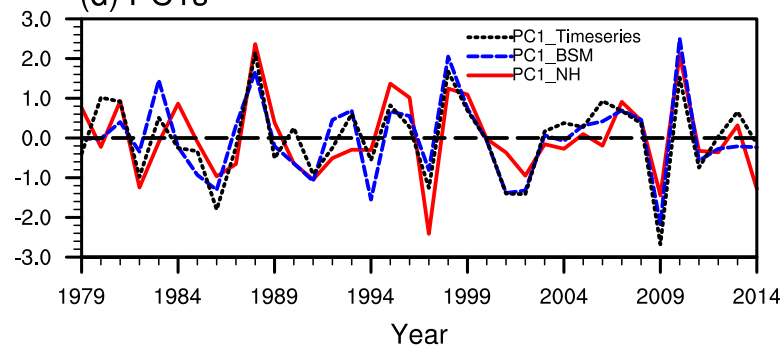

FIG. 2. The first leading mode of EOF analysis on the interannual variation of May-September (MJJAS) rainfall (a) over the Northern Hemisphere between the equator and $60^{\circ} \mathrm{N}$ and (b) over the BSM domain. (c) First leading EOF mode of the time series of the areaaveraged summer rainfall anomalies over each BSM subregion. (d) Temporal evolution of the related principal component for the first leading modes, respectively. The black frames in (b) indicate the BSM domains. Here we treat the first EOF mode in (b) as the dominant covariation mode of the BSM rainfall anomalies, and its corresponding principal component is referred to as PC1 hereafter.

$1.9^{\circ} \times 2.5^{\circ}$ with a vertical resolution of 27 levels. CAM5.1 had widely been used to investigate the features and evolution of monsoon systems (Zhou et al. 2009; Vinoj et al. 2014; Yu et al. 2015; Ma et al. 2016). The detailed designs of numerical experiments will be discussed in section $5 \mathrm{c}$.

\section{Interannual dominant covariation mode of the BSM}

\section{a. Spatial pattern}

The interannual dominant covariation mode of the BSM rainfall acts as the consistent first EOF leading mode obtained in the three different ways. In the EOF analysis of the rainfall anomalies in the Northern Hemisphere, the first EOF leading mode explains $9.5 \%$ of the total variance. When the summer rainfall is less than normal over the WNP, tropical Pacific, and midlatitudinal Atlantic Ocean, it is greater than normal over the other BSM subregions including the IND, NAM, NAF, and EA (Fig. 2a). When we focus on the rainfall anomalies within the BSM domain, the results are almost same (Fig. 2b), suggesting that the BSM covariation mode represents the interaction among the rainfall anomalies over the BSM subregions, rather than being forced by the convection over the nonmonsoonal area. The explained variance of the BSM covariation mode rises to $13.6 \%$ in this way. In this mode, when the rainfall increases over the southern IND area, most of the EA land surface, and the NAM and NAF monsoon domains, with its center settling in the NAM region, it decreases from the tropical central-western Pacific to the northern Bay of Bengal, with its center over the southern WNP area (Fig. 2b). Furthermore, principal component analysis (PCA) (Quadrelli et al. 2005) of the area-averaged rainfall indexes of the five BSM members shows a similar mode, in which the rainfall variation over the WNP is out of phase with that over the other BSM subregions, along with an explained variance of $39.0 \%$ (Fig. 2c). The PC1 results obtained by the EOF/ PCA analysis in the distinct ways resemble each other, and exhibit a strong year-by-year variation (Fig. 2d), suggesting that the interannual covariation mode of the BSM exists objectively regardless of the domain selection. Hereafter, we define the interannual dominant covariation mode of the BSM as the first EOF leading mode based on the interannual changes of rainfall within the BSM domain (Fig. 2b), and its corresponding PC1 is used for measuring the temporal evolution of this mode (Fig. 2d). Since a significant decadal change associated with the phase transition of Pacific decadal oscillation (PDO) was detected around 1993 (Lee et al. 2014), we 
have compared the behavior of this mode between 1979-93 and 1994-2014 (figure not shown). The results suggest that the BSM covariation mode exists in the different episode, but it is weaker [standard deviation (STD) is 0.62] in the early period and becomes stronger (STD is 0.85) in the later one.

The characteristics of the rainfall anomalies regressed against the PC1 are shown in Fig. 3a. When the PC1 is positive, the summer rainfall is suppressed from the tropical central-western Pacific to the northeastern Bay of Bengal, with its center over the southwestern WNP. In the meantime, the precipitation gets enhanced over the southwestern IND, the mei-yu rain belt over EA, and the oceanic areas of the NAF and the NAM monsoon regions (Fig. 3a). As a consistence of the spatial structure of the first EOF mode (Fig. 2b), it validates that the PC1 can be regarded as the IAV of the BSM dominant covariation mode.

\section{b. Circulation structure}

The IAV of the BSM dominant covariation mode is associated with the anomalous atmospheric circulation at multiple levels. In the lower troposphere, when the PC1 is positive with less than normal summer rainfall over the WNP, a remarkable anticyclonic anomaly appears to induce the abnormal moisture divergence in situ (Fig. 3b). Meanwhile, more moisture is transported to the EA by the enhanced southwesterly wind on the northern edge of this anomalous WNP anticyclone (Fig. 3b), leading to abnormal moisture convergence and greater than normal precipitation in the EA (Fig. 3a). Over the southwestern IND region, the anomalous easterly wind to the southwest of the anomalous WNP anticyclone provides sufficient moisture to enhance the local monsoon precipitation (Figs. 3a,b). Over the eastern Pacific, greater than normal summer monsoon rainfall over the NAM region corresponds to stronger low-level moisture convergence, which is induced by the tropical anomalous southwesterly wind from the equator (Figs. 3a,b). Meanwhile, the oceanic precipitation over the NAF monsoon region is enhanced, along with the low-level moisture convergence (Figs. 3a,b). In the mid-upper troposphere, along with the suppressed summer rainfall (Fig. 3a), the anomalous descending air mass and convergence zone prevails at $500 \mathrm{hPa}$ over the WNP (Fig. 3c), accompanied by a westerly anomaly at $200 \mathrm{hPa}$ (Fig. 3d). Meanwhile, the stronger ascending air mass and upper divergence zone emerges over the other four BSM subregions, corresponding to the enhanced local monsoon precipitation (Figs. 3a,c,d).

In addition, the vertical structure of the circulation and atmospheric heat source associated with the IAV of the BSM dominant covariation mode is shown in Fig. 4. The atmospheric heat source and moisture sink (i.e., condensation heating released by convection) can be expressed by the apparent heat source $\left(Q_{1}\right)$ and moisture sink $\left(Q_{2}\right)$, respectively, as follows (Yanai et al. 1973):

$$
\begin{aligned}
& Q_{1}=C_{p}\left[\frac{\partial T}{\partial t}+\mathbf{V} \cdot \nabla T+\left(\frac{p}{p_{0}}\right)^{\frac{R}{C_{p}}} \omega \frac{\partial \theta}{\partial p}\right] \\
& Q_{2}=-L_{w}\left(\frac{\partial q}{\partial t}+\mathbf{V} \cdot \nabla q+\omega \frac{\partial q}{\partial p}\right),
\end{aligned}
$$

where $C_{p}=1005 \mathrm{~J} \mathrm{~kg}^{-1} \mathrm{~K}^{-1}$ and $L_{w}=2.5 \times 10^{6} \mathrm{~J} \mathrm{~kg}^{-1} \mathrm{de}-$ note the specific heat of dry air at constant pressure and the condensation heat coefficient, respectively; $T$ and $R$ indicate the air temperature and the gas constant of dry air, respectively. As to the vertical structure of anomalous circulation, the decreased WNP monsoon rainfall is accompanied by the stronger local descending anomalies and vertical westerly shear (Figs. 4a,b). The lowlevel easterly anomalies reach the IND region and merge into the local anomalous ascending, contributing to the enhanced IND monsoon rainfall that releases more condensation heating (Fig. 4b). This generates a closed local zonal circulation over the Indo-western Pacific Ocean. To the east of the WNP, another closed zonal circulation anomaly exists over the tropical eastern Pacific and tropical western Atlantic, which consists of the anomalous descending and ascending branches over the tropical eastern Pacific and NAM region, respectively (Fig. 4a). The two anomalous zonal circulations are coupled near the date line to link the WNP, IND and NAM monsoon systems together. Meanwhile, although the low-level circulation anomalies are relatively weak near the NAF region, an abnormal upperlevel easterly emerges from the anomalous easterlies over the IND monsoon region (Fig. 4a), indicating an internal association between the IND and NAF monsoons. For the enhanced EA monsoon rainfall, it is accompanied by the weaker WNP monsoon precipitation via the meridional circulation anomalies over the EA, along with its descending branch over the WNP and its ascending branch over southern EA (Fig. 4c). The anomalous upper-level northerly above and low-level southerly below the center of stronger diabatic heating over the southern EA (Figs. 4c,d) can be explained by a Sverdrup balance between the ascending and the vertical northerly shear in situ (Liu et al. 2001). Besides, another meridional circulation anomaly appears to the south of the WNP, whose ascending branch is settled near the equator, indicating the seesaw association between the IAV of the ITCZ and the WNP monsoon 
(a) Regression of GPCP/CMAP Pr.

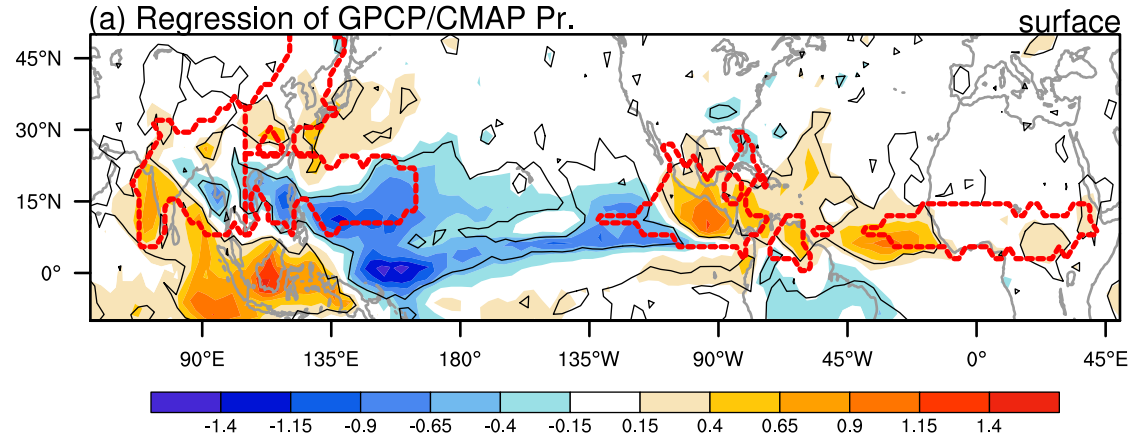

(b) Regression of $\mathrm{q}^{*} \mathrm{U} \mathrm{q}^{*} \mathrm{~V}$ and Flux

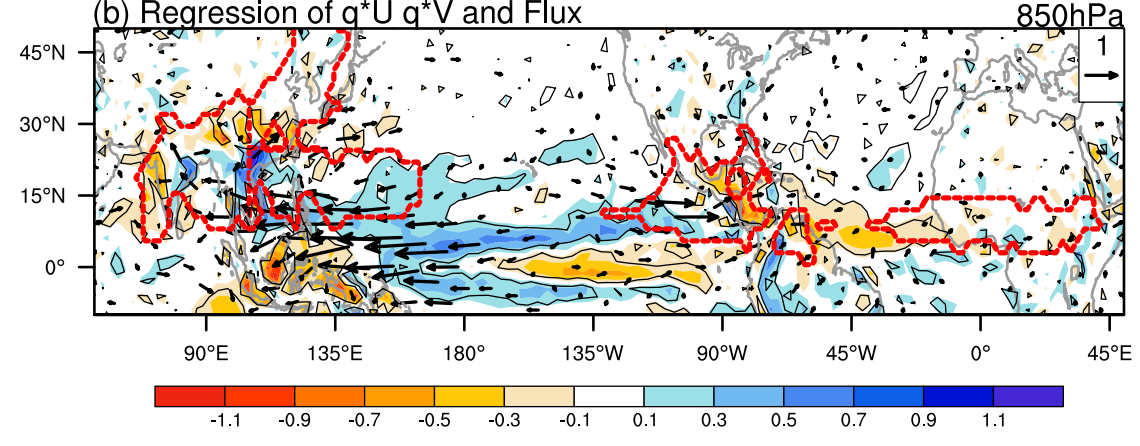

(c) Regression of UV and Omega
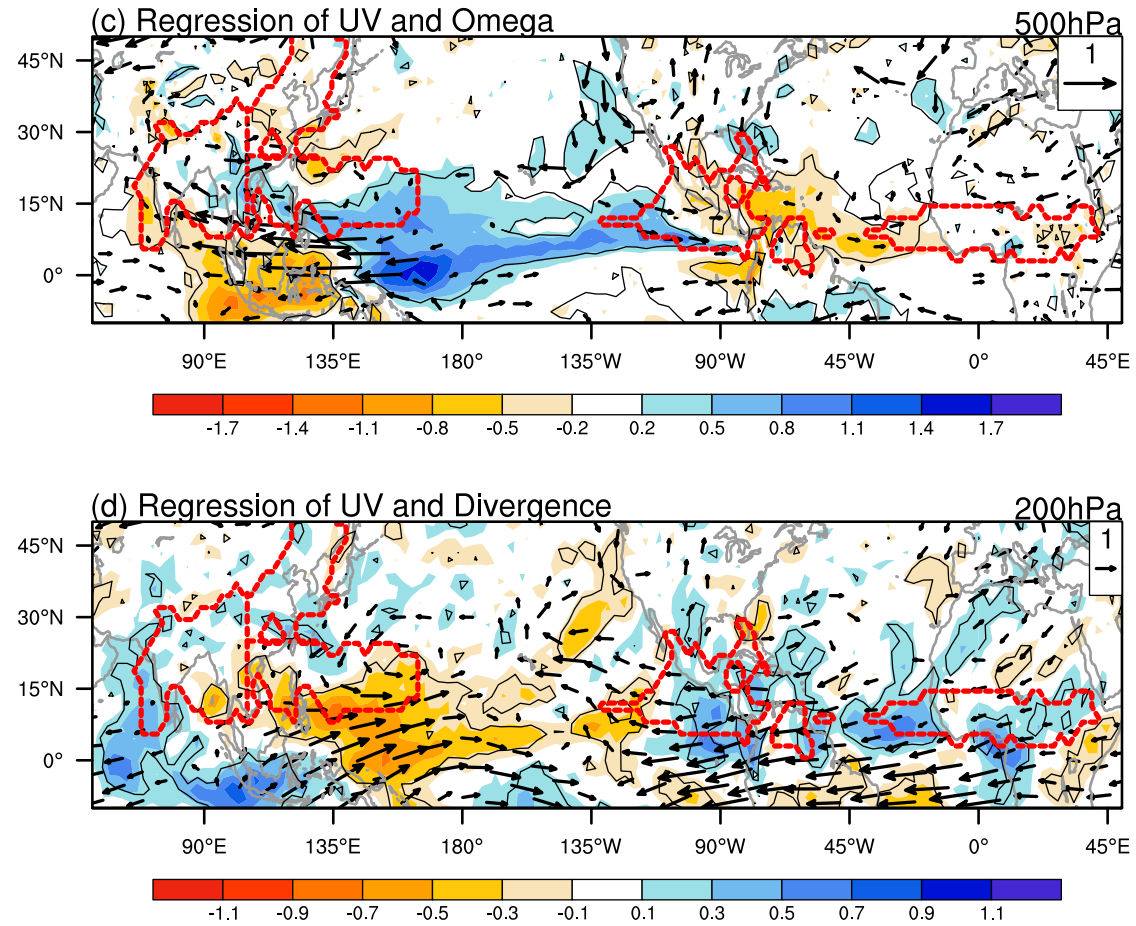

FIG. 3. Regressed MJJAS (a) rainfall (shading; intervals $0.25 \mathrm{~mm} \mathrm{day}^{-1}$ ), (b) $850-\mathrm{hPa}$ water vapor transport (vectors; $10^{-2} \mathrm{~kg} \mathrm{~m} \mathrm{~kg}^{-1} \mathrm{~s}^{-1}$ ) and its divergence (shading; intervals $2 \times 10^{-9} \mathrm{~kg} \mathrm{~kg}^{-1} \mathrm{~s}^{-1}$ ), (c) 500-hPa wind (vectors; $\mathrm{m} \mathrm{s}^{-1}$ ) and vertical motion (shading; intervals $3 \times 10^{-2} \mathrm{~Pa} \mathrm{~s}^{-1}$ ), and (d) 200-hPa wind (vectors; $\mathrm{m} \mathrm{s}^{-1}$ ) and divergence (shading; intervals $2 \times 10^{-7} \mathrm{~s}^{-1}$ ) against PC1 during 1979-2014. Only vectors exceeding the $90 \%$ confidence level are plotted. Black contours denote values exceeding the $90 \%$ confidence level and red frames indicate the BSM domains. 


\section{(a) $5^{\circ}-20^{\circ} \mathrm{N}$}

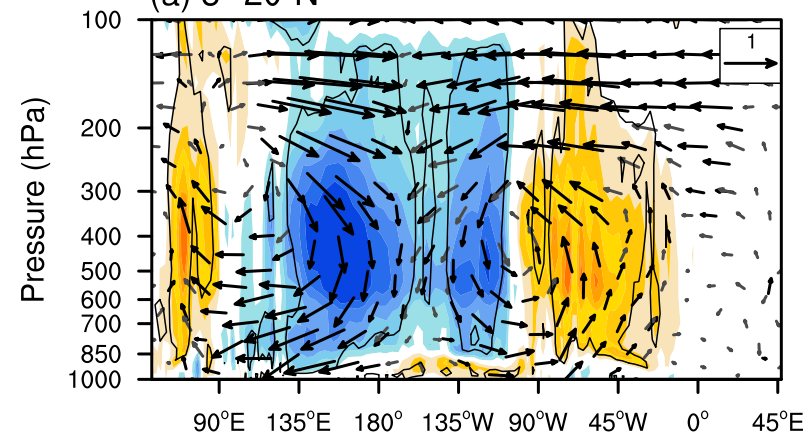

(c) $105^{\circ}-155^{\circ} \mathrm{E}$

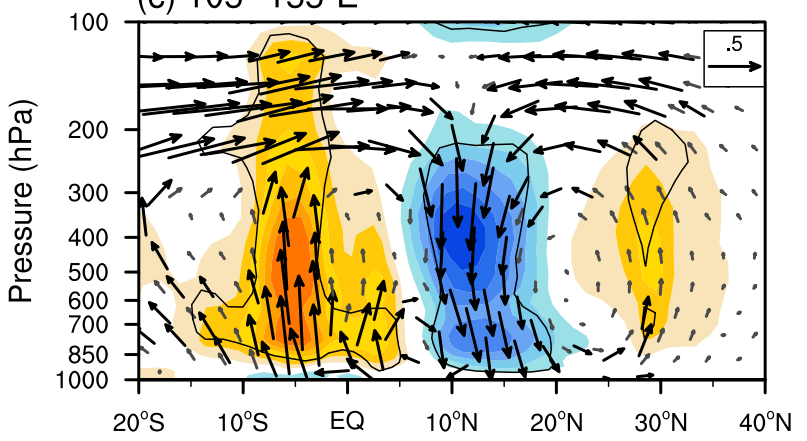

(e) $100^{\circ}-80^{\circ} \mathrm{W}$

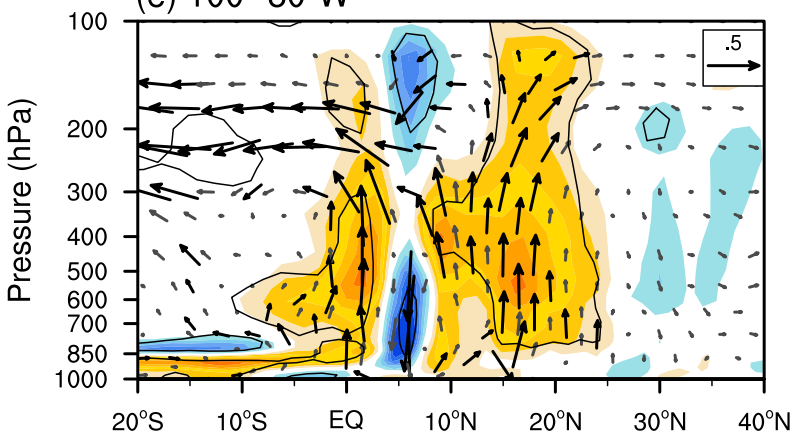

(b) $5^{\circ}-20^{\circ} \mathrm{N}$

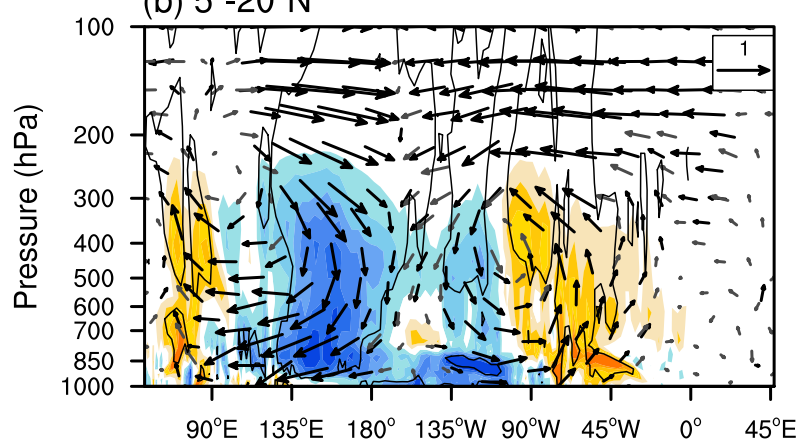

(d) $105^{\circ}-155^{\circ} \mathrm{E}$
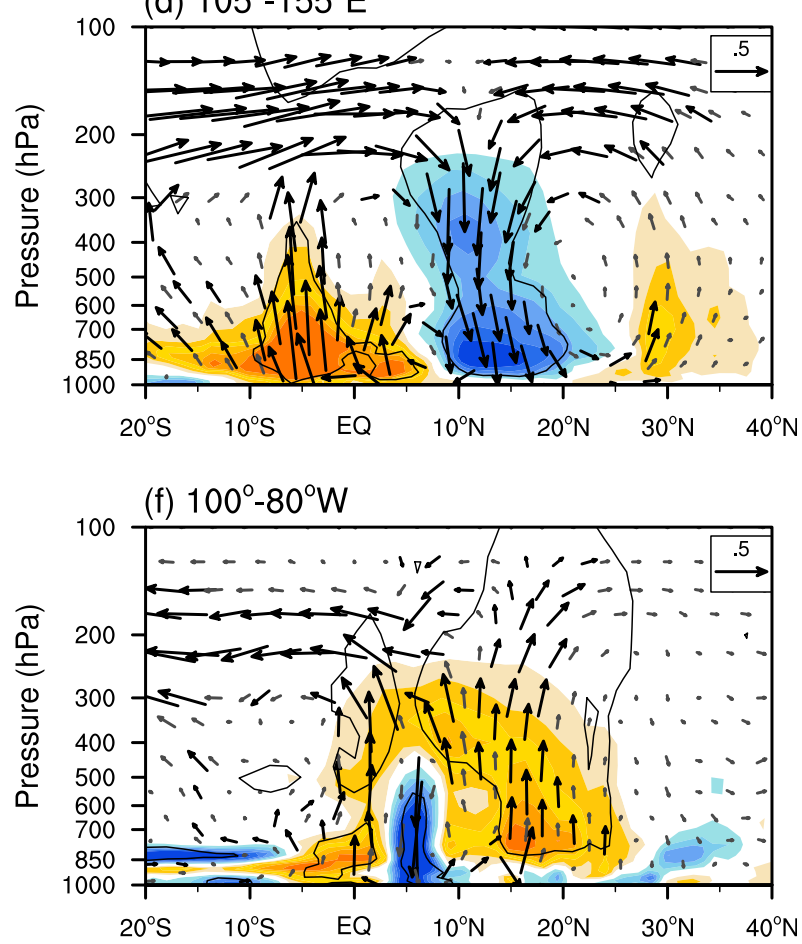

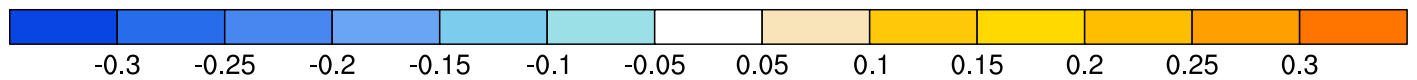

FIG. 4. (a) $5^{\circ}-20^{\circ} \mathrm{N}$ averaged pressure-longitudinal, (c) $105^{\circ}-155^{\circ} \mathrm{E}$ averaged pressure-latitudinal, and (e) $100^{\circ}-80^{\circ} \mathrm{W}$ averaged pressure-latitudinal cross sections of the circulation (vectors; $\mathrm{m} \mathrm{s}^{-1}$; vectors exceeding the $90 \%$ confidence level are drawn in black) and $Q_{1}$ (shading interval $0.05 \mathrm{~K} \mathrm{day}^{-1}$ ) anomalies in MJJAS regressed against PC1 during 1979-2014. (b),(d),(f) As in (a),(c),(e), respectively, but the shadings are for the regressed $Q_{2}$ (shading interval $0.05 \mathrm{~kg}_{\text {day }}{ }^{-1}$ ) values. Values of $Q_{1}$ and $Q_{2}$ exceeding the $90 \%$ confidence level are contoured in black.

rainfall (Figs. 4c,d). For the NAM region, the meridional circulation is distinct from that of in the WNP region. In particular, the local ascending anomaly over the NAM is linked with the stronger descending over the equatorial eastern Pacific, implicating its connection with the SSTAs in the equatorial Pacific Ocean (Figs. 4e,f).

As a result, the BSM dominant covariation mode represents the interaction among the five BSM members via a series of vertical coupling process between the upper- and lower-level circulations on the interannual time scale. In particular, the WNP summer monsoon connects the EASM via the north-south-oriented circulation with the remarkable vertical structure in the extratropics. The WNP monsoon can influence the IND monsoon rainfall via a deep zonal circulation over the Indo-western Pacific Ocean. It also links to the NAM 
TABLE 1. The standard deviation (STD) of the interannual variability of monsoon rainfall for each BSM member and the explained variance (Exp. var.) of the leading covariation mode to the total interannual variability of each BSM member. The EOF stability index (SI) is defined as the product of the anomaly correlation coefficient (ACC) between the EOF modes and the temporal correlation coefficient (TCC) between the corresponding principal components. Here we have excluded one BSM member at a time to reproduce the EOF analysis, and calculated its EOF SI.

\begin{tabular}{|c|c|c|c|c|c|}
\hline & IND & WNP & EA & NAM & NAF \\
\hline STD $\left(\mathrm{mm} \mathrm{day}^{-1}\right)$ & 0.49 & 0.77 & 0.36 & 0.63 & 0.3 \\
\hline Exp. var. (\%) & 17.76 & 42.44 & 17.66 & 46.67 & 31. \\
\hline SI & 0.96 & 0.78 & 0.99 & 0.88 & 0.9 \\
\hline
\end{tabular}

monsoon through another zonal circulation over the tropical eastern Pacific. The NAF monsoon joins this mode by the upper-level zonal circulation coming from the IND monsoon region. In the following sections, we will investigate the possible reason for the maintain of the BSM dominant covariation mode.

\section{Internal association of rainfall anomalies in the BSM}

\section{a. Statistical analysis}

The BSM dominant covariation mode features a combination of the five BSM members, but the contribution of each member to this mode is unbalanced. Compared with the other BSM members, the greatest STD of rainfall IAV occurs over the WNP and NAM regions, and nearly half of their IAV can be ascribed to the PC1 (Table 1). It indicates that the major contributor to the BSM dominant covariation mode is the IAV of the WNP and NAM monsoons. On the other hand, the relative importance of each BSM member is also verified by the EOF stability index (SI), which is defined as a product of the anomaly correlation coefficient (ACC) between the modes and the temporal correlation coefficient (TCC) between the corresponding PCs obtained by the EOF analysis of the different combinations of BSM members (Pang et al. 2014). Here we leave one BSM member out at a time to reproduce the EOF analysis on the remainder, and calculate the EOF SI between the new results and the original one. A lower EOF SI in the leave-one-out case indicates a greater importance of the removed member in the BSM dominant covariation mode. It shows that the WNP monsoon rainfall is most important for the leading covariation mode of the BSM owing to the largest decrease of the SI to 0.78 , followed by the NAM monsoon rainfall, whose SI declines to 0.88 (Table 1); the other BSM members exhibit relatively less contribution to the BSM dominant covariation mode.

\section{b. LBM results}

As shown in Fig. 5a, the abnormal diabatic heating and cooling within the BSM domain is most significant over the NAM and WNP, respectively. Meanwhile, the large diabatic heating and cooling anomalies outside the BSM domain are located over the Maritime Continent (MC) and the equatorial western Pacific (EWP), respectively (Fig. 5a). A series of sensitivity experiments using the LBM are designed to validate the role of these diabatic forcing in the BSM dominant covariation mode. The horizontal distribution of the given diabatic forcing is shown in Fig. 5a, while their vertical structure is presented in Figs. 5b-e. More details are listed in Table 2. In each LBM sensitivity experiment, the LBM is integrated for 30 days and the mean values in the last 15 days are treated as the stationary atmospheric response to the diabatic heating or cooling.

Although the LBM lacks circulation-precipitation feedback, the circulation anomalies associated with the BSM covariation mode can be qualitatively reproduced when the diabatic forcing is given in the WNP and NAM regions. In particular, when the diabatic cooling and heating are situated in the WNP and NAM as shown in Figs. 5a-c, it is inevitable that anomalous descending and ascending occur respectively over these two regions (Fig. 6b). This corresponds to the anomalies of low-level anticyclone and upper-level convergence over the WNP, as well as the abnormal low-level cyclone and upperlevel divergence over the NAM (Figs. 6a,c). Outside the diabatic forcing regions, the WNP-NAM experiment could well simulate the anomalous ascending in the middle troposphere and the upper-level divergence anomalies over the IND, NAF, and EA regions (Figs. 6b,c), consistent with the local anomalous rainfall (Fig. 3a). Compared with observations, although the WNP-NAM experiment can capture the low-level cyclone anomaly over the EA, it cannot well capture the cyclone anomalies in the lower troposphere of the NAF and IND (Fig. 6a). It verifies that the NAF monsoon join in the BSM dominant covariation mode by the IAV of the mid- to upper-level circulation as shown in Fig. 4a. As for the IND region, the conflict between the WNPNAM experiment and observations suggests the importance of circulation-precipitation feedback in this region, without which the low-level WNP anticyclone anomaly could extend unrealistically onto the IND in the WNP-NAM experiment. However, the diabatic heating over the MC and cooling over the EWP cannot lead to reasonable circulation anomalies over the BSM domain in the LBM (Figs. 6a-c) despite the greater intensity (Figs. 5a,d,e), suggesting that the BSM dominant covariation mode is maintained by the interaction 
(a) Levels-integralled Observation and Experiments
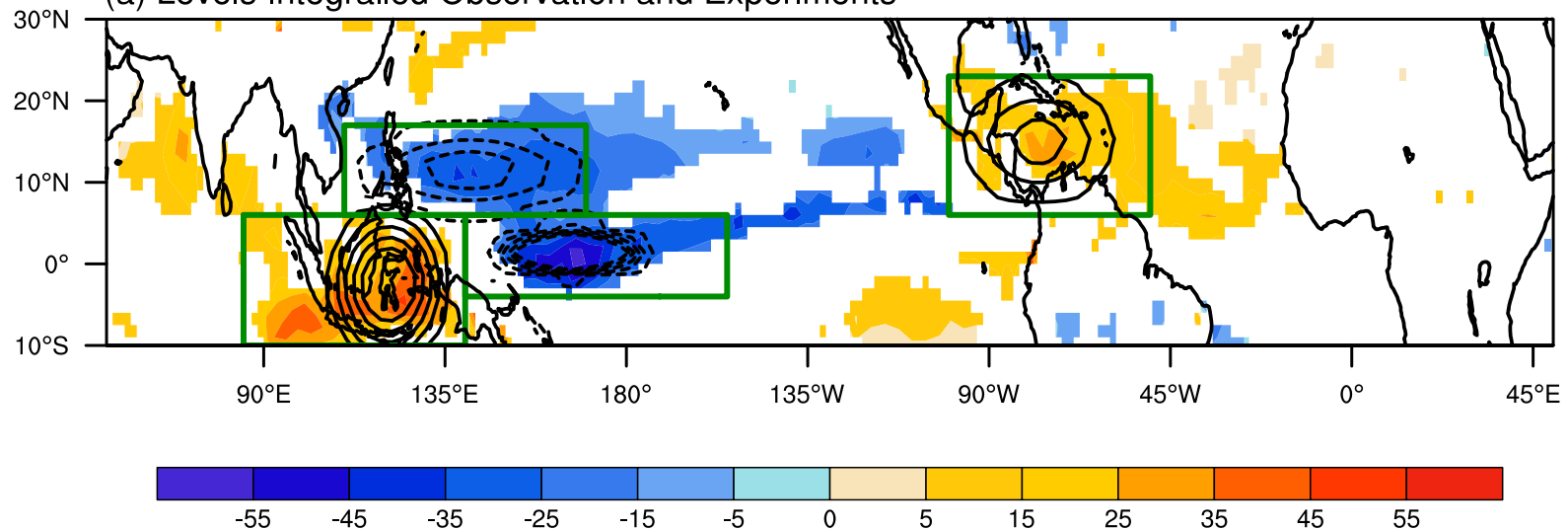

(b) WNP-cooling Experiment

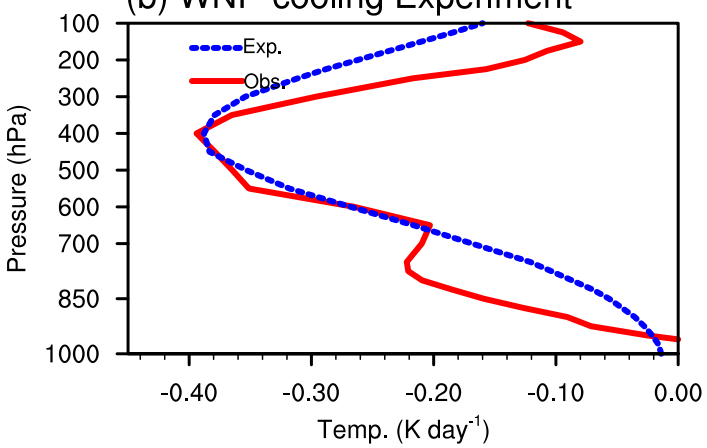

(d) EWP-cooling Experiment

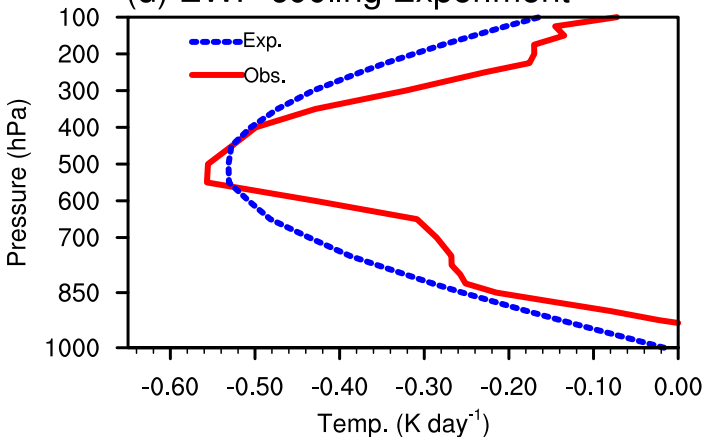

(c) NAM-heating Experiment

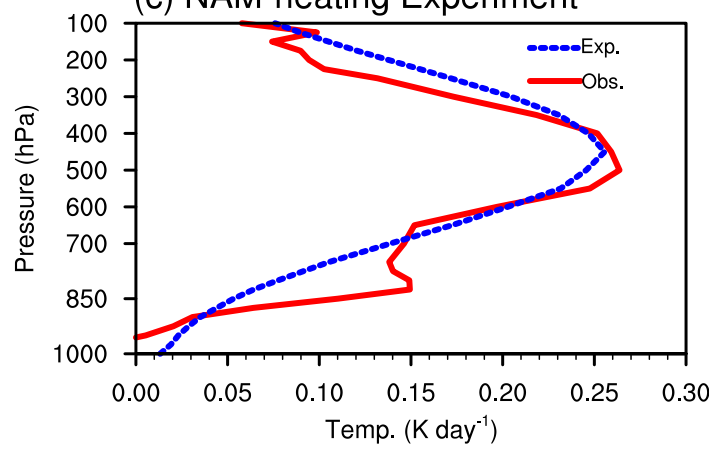

(e) MC-heating Experiment

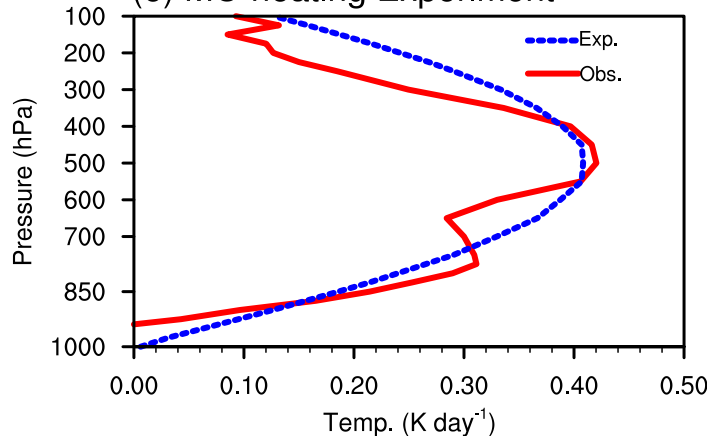

FIG. 5. (a) The tropospheric integrated $Q_{1}$ (shading; interval by $10 \mathrm{~K} \mathrm{day}^{-1}$, only values exceeding the $90 \%$ confidence level are plotted) regressed against PC1 and the corresponding tropospheric integrated $Q_{1}$ (contour; interval by $10 \mathrm{~K}_{\text {day }}{ }^{-1}$ ) in the LBM experiments. Solid (dashed) contours denote the forcing of diabatic heating (cooling). The green boxes are the WNP, NAM, EWP, and MC regions. (b)-(e) Vertical profiles of $Q_{1}$ over the WNP, NAM, EWP, and MC regions, respectively. The red solid line denotes the observed $Q_{1}$ anomaly regressed against PC1; the blue dashed line represents the diabatic forcing in the LBM experiments.

among all BSM members. When all the diabatic forcings in Fig. 5a are given, the LBM is able to produce the observed circulation anomalies at each level (Figs. 6a-c). Therefore, the BSM dominant covariation mode is determined by the diabatic heating related to the abnormal WNP and NAM convection, while the MC and
EWP diabatic forcing outside the BSM domain could modulate the strength of this mode. Both statistical and LBM experiments suggest that the IAV of summer rainfall over the WNP and NAM is critical to maintain the BSM dominant covariation mode on the interannual time scale. 
TABLE 2. Designation of the sensitivity experiments using the linear baroclinic model (LBM).

\begin{tabular}{lcr}
\hline \hline \multicolumn{1}{c}{ Name } & Area & Forcing center value and its location \\
\hline WNP-cooling experiment & $110^{\circ}-170^{\circ} \mathrm{E}, 6^{\circ}-17^{\circ} \mathrm{N}$ & $-0.38 \mathrm{~K} \mathrm{day}{ }^{-1} ; 12^{\circ} \mathrm{N}, 140^{\circ} \mathrm{E} ; 400 \mathrm{hPa}$ \\
NAM-heating experiment & $110^{\circ}-50^{\circ} \mathrm{W}, 6^{\circ}-23^{\circ} \mathrm{N}$ & $0.22 \mathrm{~K} \mathrm{day}{ }^{-1} ; 16^{\circ} \mathrm{N}, 75^{\circ} \mathrm{W} ; 500 \mathrm{hPa}$ \\
MC-heating experiment & $80^{\circ}-140^{\circ} \mathrm{E}, 10^{\circ} \mathrm{S}-6^{\circ} \mathrm{N}$ & $0.40 \mathrm{~K} \mathrm{day}{ }^{-1} ; 3^{\circ} \mathrm{S}, 125^{\circ} \mathrm{E} ; 500 \mathrm{hPa}$ \\
EWP-cooling experiment & $140^{\circ} \mathrm{E}-155^{\circ} \mathrm{W}, 4^{\circ} \mathrm{S}-6^{\circ} \mathrm{N}$ & $-0.55 \mathrm{~K} \mathrm{day}{ }^{-1} ; 0^{\circ}, 170^{\circ} \mathrm{E} ; 500 \mathrm{hPa}$ \\
WNP-NAM experiment & The combined WNP-cooling and NAM-heating experiment \\
MC-EWP experiment & The combined MC-heating and EWP-cooling experiment \\
All experiment & The combined WNP-NAM and MC-EWP experiment \\
\hline
\end{tabular}

The above regression analysis shows the evident phase transition of the BSM dominant covariation mode, whereas the IAV of its strength can be measured by the magnitude of PC1. Since the primary contributors to this mode are the WNP and NAM summer monsoons, we speculate that the strength of PC1 should be closely associated with the interaction between the IAV of these two summer monsoons. Figures $7 \mathrm{a}$ and $7 \mathrm{~b}$ show that the WNP rainfall is significantly negative correlated with the NAM precipitation $(\mathrm{TCC}=-0.31)$. Both the IAVs of WNP and NAM rainfall are closely correlated with the PC1, yielding a TCC of -0.66 and 0.64 , respectively. Also, the magnitude of $\mathrm{PC} 1$ becomes larger $(\mathrm{STD}=0.85)$ when the IAVs of the WNP and NAM rainfall are out of phase, but it decreases apparently $(\mathrm{STD}=0.61)$ when the rainfall varies in phase between these two regions. It implies that the IAV of the strength of the BSM dominant covariation mode is associated with the phase relationship of the rainfall anomalies between the WNP and NAM monsoon regions. As the WNP and NAM monsoons are settled on the western and eastern side of the tropical Pacific, respectively, the phase relationship between their IAV of rainfall should be modulated by ENSO events, which is the most prominent interannual air-sea variability in the tropical Pacific.

\section{External linkages to ENSO events}

According to the Climate Prediction Center criteria, the Oceanic Niño Index (ONI) has become the de facto standard that the National Oceanic and Atmospheric Administration (NOAA) uses for identifying ENSO events in the tropical Pacific. It is the running 3-month mean SSTA for the Niño-3.4 region (i.e., $5^{\circ} \mathrm{N}-5^{\circ} \mathrm{S}, 120^{\circ}-$ $\left.170^{\circ} \mathrm{W}\right)$. Events are defined as five consecutive overlapping 3-month periods at or above the $+0.5^{\circ}$ anomaly for warm (El Niño) events and at or below the $-0.5^{\circ}$ anomaly for cold (La Niña) events (http://origin.cpc. ncep.noaa.gov/products/analysis_monitoring/ensostuff/ ONI_v5.php). Then the ENSO events are sorted into four groups based on the phase relationship of the rainfall anomalies between the WNP and NAM monsoon regions and its corresponding strength of the BSM covariation mode. In particular, the ENSO events preceding the inphase decrease or increase of WNP and NAM rainfall are included in the weak 1 (W1) and weak 2 (W2) categories, respectively. The strong 1 (S1) and strong 2 (S2) categories include the ENSO events followed by the out-of-phase variation of WNP and NAM precipitation, respectively. More specifically, the decreased WNP rainfall occurs along with the increased NAM rainfall in the S1 category, and the opposite situation takes place in the S2 category. The selected events in each category are listed in Table 3. In the years with out-of-phase variation of rainfall anomalies between the WNP and NAM monsoon regions, the magnitude of PC1 becomes larger (STD is 1.14 and 0.93 for S1 and S2, respectively) than in the inphase years (STD is 0.63 and 0.40 for W1 and W2, respectively). Such difference is ascribed to the distinct seasonal evolution of the previous ENSO events and the resultant tropical SSTAs.

\section{a. Tropical SSTAs associated with the strong modes}

The out-of-phase relationship between the WNP and NAM rainfall anomalies, representing the S1 and S2 categories, indicates a strong BSM dominant covariation mode. In the S1 category with the decreased WNP rainfall and increased NAM monsoon rainfall (Fig. 8a), the summertime warm SSTA emerges in the tropical Indian Ocean, with its center around the MC, while the cold SSTA exists in the equatorial central-eastern Pacific (Fig. 8b). The warm SSTA is accompanied by the stronger ascending flow, which descends over the WNP to suppress the local monsoon convection (Fig. 8d). On the one hand, the descending anomaly induces the stronger geopotential height $(\mathrm{GPH})$ at $925 \mathrm{hPa}$, consistent with the abnormal low-level anticyclone that facilitates the further warming of local SST (Figs. 8b,d). It indicates the atmospheric forcing on the SSTA in the WNP. On the other hand, the atmospheric subsidence anomaly over the WNP joins in a closed zonal circulation anomaly over the Indo-western Pacific Ocean. To the east of the WNP, another closed zonal circulation anomaly exists over the 
(a) Vorticity

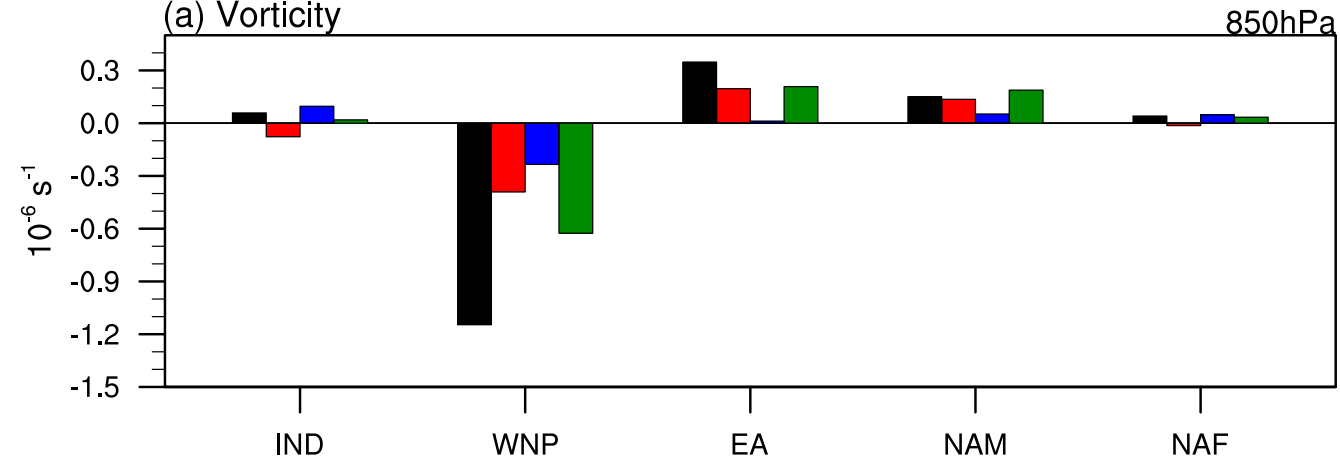

(b) Omega

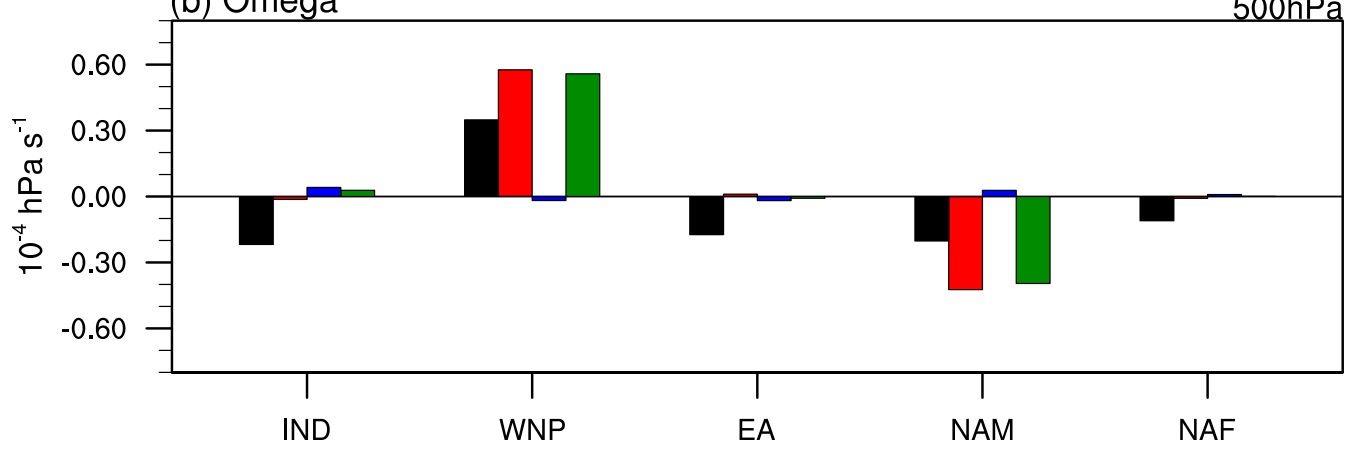

(c) Divergence

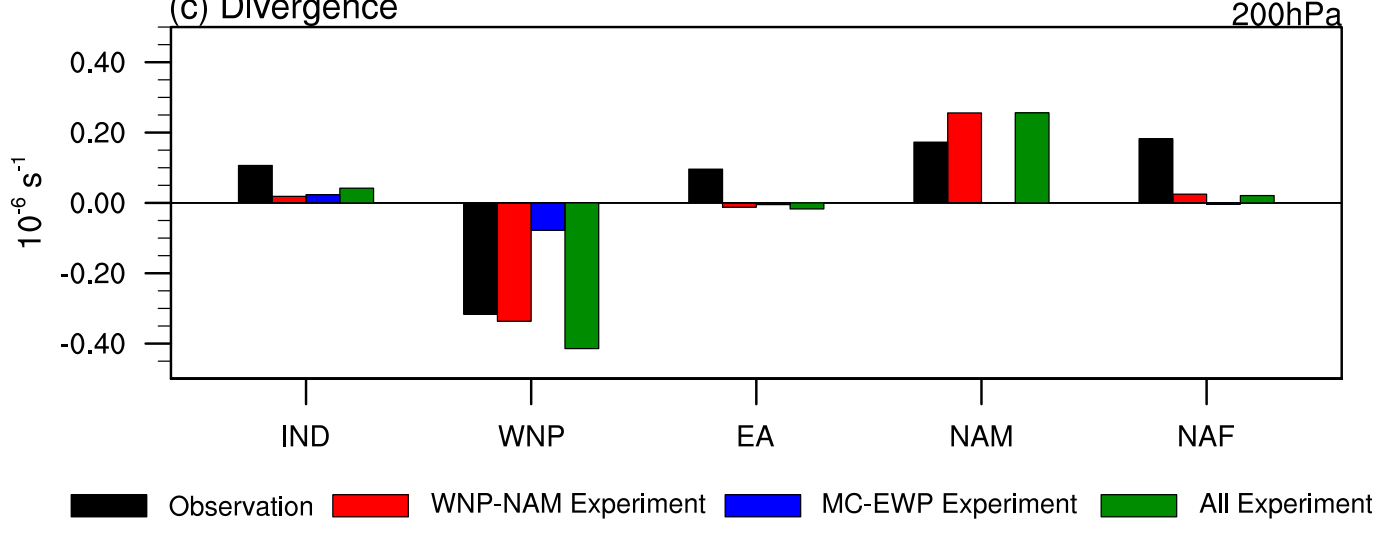

FIG. 6. Comparison of observed regression against PC1 (black bars), circulation response of the WNP-NAM experiment (red bars), the MC-EWP experiment (blue bars), and all experiments combined (green bars) in the LBM. Area-averaged values are calculated over the five approximate BSM subregions for (a) vorticity (unit $10^{-6} \mathrm{~s}^{-1}$ ) at $850 \mathrm{hPa}$, (b) omega (unit $10^{-4} \mathrm{~Pa} \mathrm{~s}^{-1}$ ) at $500 \mathrm{hPa}$, and (c) divergence (unit $10^{-6} \mathrm{~s}^{-1}$ ) at $200 \mathrm{hPa}$.

NAM region, whose ascending branch is located in the warmer North American coastal area and tropical Atlantic (Fig. 8c), corresponding to the greater than normal rainfall over the NAM. The warm SSTA within the NAM region favors the abnormal ascending in situ. Thus, the zonally coupled anomalous circulation links the decreased WNP rainfall and increased NAM rainfall anomalies together when the BSM dominant covariation mode is strong in its positive phase.
When the WNP rainfall is enhanced but the NAM rainfall is suppressed in the S2 category, the BSM dominant covariation mode turns into its strong negative phase (Fig. 9a). In this case, the SST in the tropical central Pacific and TIO is cooling down in boreal summer (Fig. 9b). Therefore, the abnormal zonal gradient of SSTA generates over the WNP, resulting in the abnormal low-level westerly over the TIO and easterly over the equatorial western Pacific. Then the anomalous 
(a) PC1, WNP Pr. and NAM Pr.

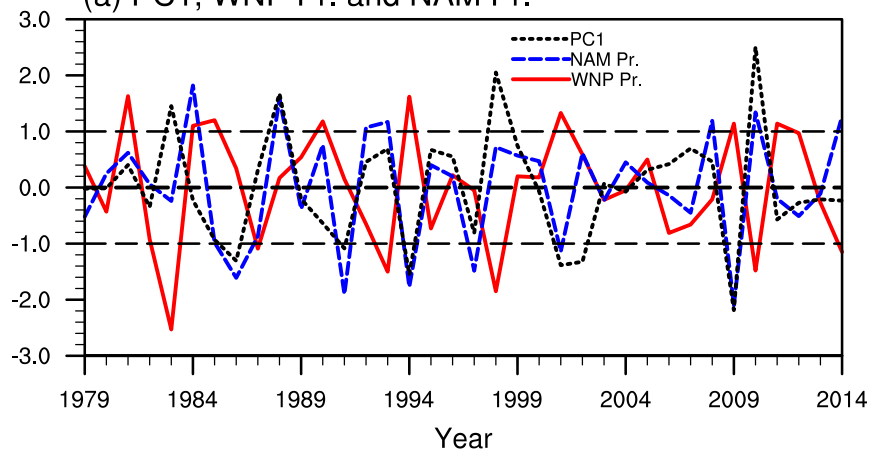

(b) WNP Pr. and NAM Pr.

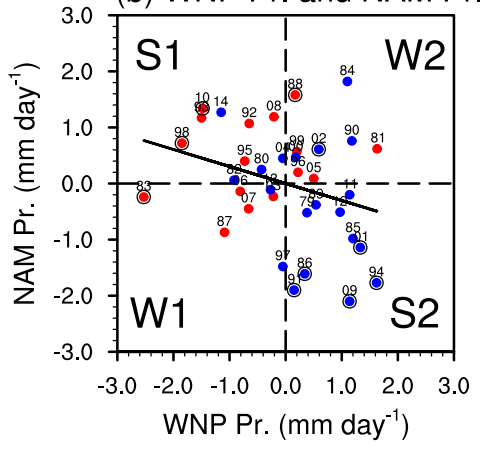

FIG. 7. (a) Time series of the standardized MJJAS rainfall index over the WNP (red solid line) and NAM (blue dashed line) domains, and the PC1 (black dashed line) during 1979-2014. (b) Scatterplot of standardized MJJAS rainfall index between the WNP and NAM domains. Red and blue dots with numbers (indicating the specific year) denote the specific years when PC1 is positive and negative, respectively. The cases with PC1 exceeding 1.0 STD are circled in black. The quadrants labeled S1, S2, W1, and W2 denote their specific category.

zonal winds converge over the WNP to enhance the local monsoon rainfall and ascending branch (Figs. 9a,c). In the meantime, the SSTA becomes colder and $925-\mathrm{hPa}$ GPH decreases over the WNP, suggesting the atmospheric forcing to the SST (Figs. 9b,c). However, the descending anomaly over the NAM region acts as an atmospheric response to the cold SSTA in the tropical central-eastern Pacific (Figs. 9b,d), consistent with the suppressed rainfall (Fig. 9a).

\section{b. Tropical SSTAs related to the weak modes}

However, the situation changes in the W1 and W2 categories with the in-phase variation of WNP and NAM rainfall on the interannual time scale, corresponding to the weak BSM dominant covariation mode. In the $\mathrm{W} 1$ category, the monsoon rainfall is suppressed over both the WNP and NAM monsoon regions (Fig. 10a), and warm SSTAs in boreal summer arise in the TIO and equatorial eastern Pacific (Fig. 10b), where the ascending is enhanced (Fig. 10c). The abnormal ascending over the TIO subsides over the WNP to strengthen the local low-level divergence and descending, and

TABLE 3. The four categories (first column) classified according to relationships between MJJAS rainfall anomalies over the WNP and NAM monsoon regions (second and third columns), and their included typical ENSO events (fourth column). The plus and minus signs denote positive and negative rainfall anomalies, respectively.

\begin{tabular}{cccc}
\hline \hline Category & WNP & NAM & Typical ENSO years \\
\hline S1 & - & + & $1979 / 80,1991 / 92,1994 / 95,1997 / 98$, \\
& & & $2009 / 10$ \\
S2 & + & - & $1984 / 85,1988 / 89,2000 / 01,2008 / 09$, \\
& & & $2010 / 11,2011 / 12$ \\
W1 & - & - & $1982 / 83,1986 / 87,2002 / 03,2006 / 07$ \\
W2 & + & + & $1983 / 84,1995 / 96,1998 / 99,1999 / 00$ \\
\hline
\end{tabular}

further to inhibit the local monsoon rainfall (Figs. 10a,c). Such abnormal closed zonal circulation has been reported as a response to the warm TIO SSTA (Xie et al. 2009; Huang et al. 2010, 2011). Also, the anomalous meridional circulation with its descending over the WNP and ascending over the tropical Indo-Pacific warm pool could further restrain the WNP monsoon rainfall (Figs. 10a,d). Furthermore, the upper-level airflow emanating from the TIO could arrive at the NAM region, then subsiding to enhance the local descending, corresponding to the suppressed NAM monsoon rainfall (Figs. 10a,c).

In the W2 category, the rainfall gets enhanced together over the WNP and NAM monsoon regions (Fig. 11a), along with the evident cold SSTA in TIO and equatorial central-eastern Pacific and warm SSTA in the WNP during boreal summer (Fig. 11b). The abnormal descending occurs over the colder TIO, while the anomalies of ascending and low-level convergence appear over the warmer WNP due to the abnormal zonal winds induced by the zonal gradient of SSTA in the Indo-Pacific warm pool (Figs. 11b,c). The warm SSTA in the WNP could further amplify the ascending anomaly, and strengthens the WNP monsoon rainfall (Figs. 11a-c). Over the NAM region, the abnormal ascending and greater than normal monsoon rainfall are linked to the stronger tropical subsidence over the colder equatorial central-eastern Pacific (Fig. 11d). Thus, the SSTA forcing on the atmospheric circulation is observed in the W2 category, and the horizontal distribution of SSTA could maintain the in-phase enhancement of rainfall between the WNP and NAM regions.

The horizontal distribution of SSTA in boreal summer is distinct among the four categories sorted by the phase relationship of rainfall IAV between the WNP and 
(a) Prec.

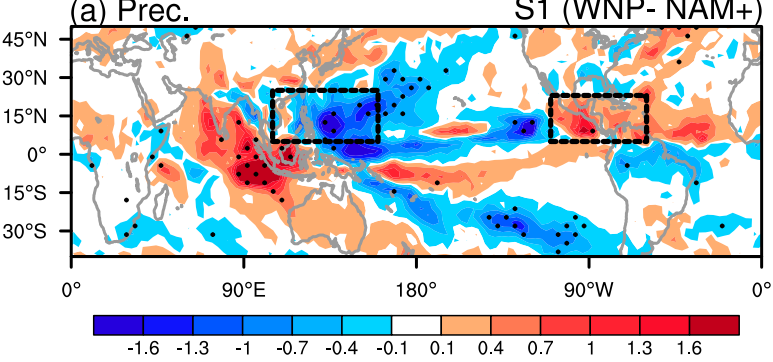

(c) Zonal Circul. \& Q1

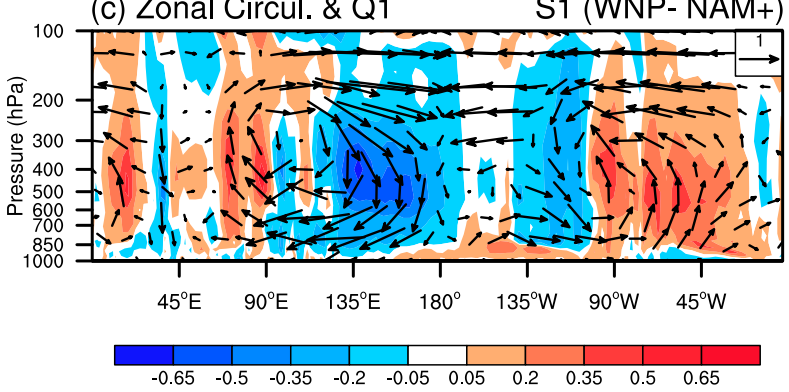

(b) SST \& HGT $925 \mathrm{hPa}$

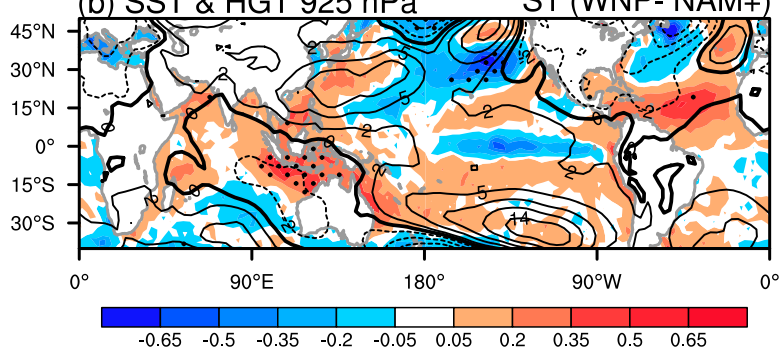

(d) Meridional Circul. \& Q1

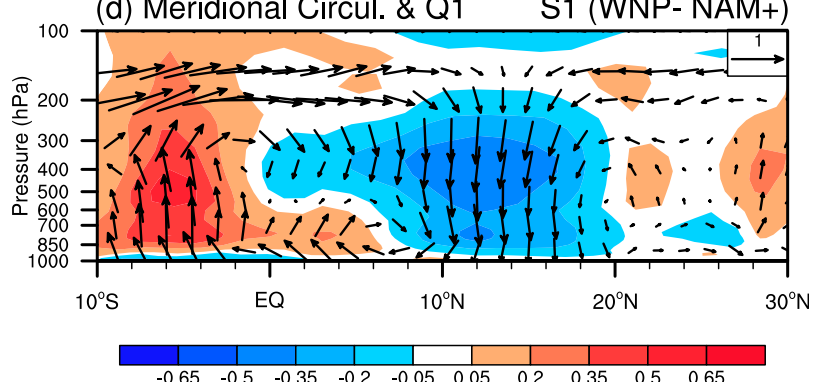

FIG. 8. Composite MJJAS (a) precipitation (shading interval $0.3 \mathrm{~mm} \mathrm{day}^{-1}$ ), (b) SST (shading interval $0.15^{\circ} \mathrm{C}$ ) and geopotential height (contour interval $3 \mathrm{~m}$ ) at $925 \mathrm{hPa},(\mathrm{c}) 5^{\circ}-20^{\circ} \mathrm{N}$ averaged pressure-longitudinal cross section of zonal circulation, and (d) $105^{\circ}-155^{\circ} \mathrm{E}$ averaged pressure-latitudinal cross section of meridional circulation over the WNP monsoon region in the S1 category. Solid (dashed) lines in (b) denote positive (negative) values. The composite precipitation and SST exceeding 90\% confidence level in (a) and (b) are stippled in black. Black dashed lines denote approximate WNP and NAM monsoon domains.

NAM regions, which is consistent with the strength changes of the BSM dominant covariation mode. Also, the SSTAs in the TIO and tropical Pacific are ascribed to the ENSO events on the interannual time scale. Generally, the anomalous WNP monsoon well corresponds to the ENSO events, say that greater (less) than normal convection occurs over the WNP after a La Niña (an El Niño) event (Figs. 12a,b). The associated physical mechanisms have been documented by many previous studies (Wang et al. 2000; Xie et al. 2009; Wu et al. 2009; Li et al. 2016). However, the interrelation of rainfall IAV between the WNP and NAM regions depends on the temporal evolution of ENSO event in the preceding seasons. Before the strong mode with out-of-phase variation of rainfall between the WNP and NAM regions, the fast decaying ENSO events take place in the previous spring, indicating that the ENSO signal disappears in May and is followed by the weak TIO SSTA in boreal summer (Figs. 12a,c). In contrast, previous to the summer season of the weak mode with in-phase variation of rainfall over the WNP and NAM regions, the ENSO events in winter could persist till early summer and cause a stronger SSTA in the TIO afterward (Figs. 12b,d). The different behavior of TIO SSTA in summer can be explained by the effect of the "atmospheric bridge" (Klein et al. 1999; Alexander et al. 2002), which is related to the distinct seasonal evolution of ENSO events. When the rainfall IAV between the
WNP and NAM is out of phase in S1 and S2 categories, the fast-decaying ENSO events in spring give rise to a weaker atmospheric bridge in the following season, presenting a small lagged correlation between TIO SSTA and wintertime Niño-3.4 index (Fig. 12e). Nevertheless, when the rainfall IAV between the WNP and NAM is in phase in the $\mathrm{W} 1$ and $\mathrm{W} 2$ categories, the atmospheric bridge after spring becomes stronger subsequent to a persisting ENSO event from winter to summer, during which the TIO SSTA is closely associated with the ENSO event in the previous winter (Fig. 12f). Therefore, the phase of BSM dominant covariation mode changes with the phase transition of the previous ENSO events, but its strength depends on the seasonal evolution of ENSO events from the previous boreal winter to the current summer.

\section{c. AGCM results}

Although the SSTA feedback to the atmospheric circulation is pronounced over the WNP, the data analysis shows that the phase relationship of rainfall IAV between the WNP and NAM (i.e., the strength of BSM dominant covariation mode) is primarily modulated by the SSTAs' forcing to the atmosphere. To validate the results of the data analysis, we designed a series of sensitivity experiments using the CAM5.1 model to examine the effects of tropical Pacific and TIO SSTAs on the BSM dominant covariation mode. The control (CTL) runs are 
(a) Prec



(c) Zonal Circul. \& Q1

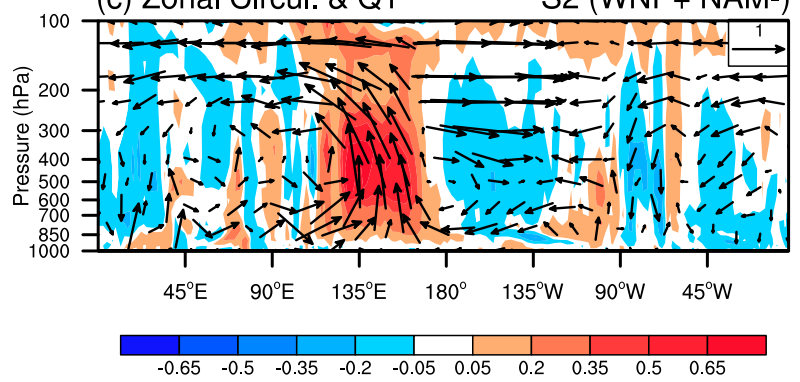

(b) SST \& HGT $925 \mathrm{hPa}$



(d) Meridional Circul. \& Q1

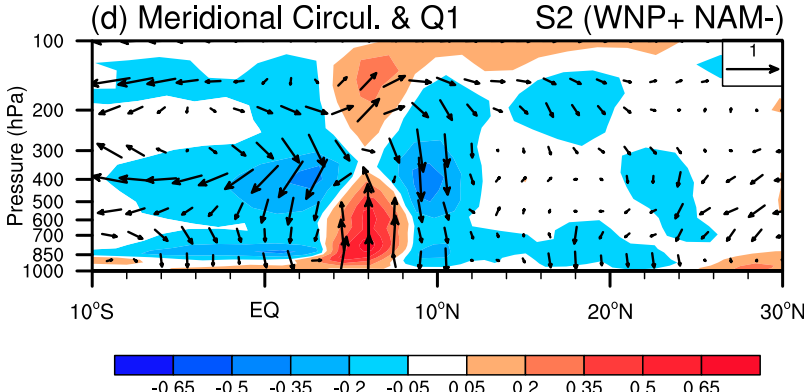

FIG. 9. Composite MJJAS (a) precipitation (shading interval $0.3 \mathrm{~mm} \mathrm{day}^{-1}$ ), (b) SST (shading interval $0.15^{\circ} \mathrm{C}$ ) and geopotential height (contour interval $3 \mathrm{~m}$ ) at $925 \mathrm{hPa}$, (c) $5^{\circ}-20^{\circ} \mathrm{N}$ averaged pressure-longitudinal cross section of zonal circulation, and (d) $100^{\circ}-80^{\circ} \mathrm{W}$ averaged pressure-latitudinal cross section of meridional circulation over the NAM monsoon region in the S2 category. Solid (dashed) lines in (b) denote positive (negative) values. The composite precipitation and SST exceeding 90\% confidence level in (a) and (b) are stippled in black. Black dashed lines denote approximate WNP and NAM monsoon domains.

driven by the climatological SST with a seasonal cycle and were integrated for 15 model years, and the sensitivity runs were based on the CTL output in the last 6 model years. Then we attached the significant SSTA in the tropical Indian and Pacific Ocean $\left(30^{\circ} \mathrm{S}-30^{\circ} \mathrm{N}, 30^{\circ} \mathrm{E}-70^{\circ} \mathrm{W}\right)$ from January to September in each category into the climatological SST, and integrated the CAM5.1 to conduct each sensitivity (SEN) run, named SEN_S1, SEN_S2, SEN_W1, and SEN_W2. Although the CTL runs have some discrepancies in reproducing the BSM domain and the subtle features of regional monsoon rainfall, they are able to capture the reasonable seasonal cycle of the global monsoon rainfall and the large-scale atmospheric circulation. Thus, a comparison between CTL and SEN runs (SEN minus CTL) could exhibit the effects of SSTA seasonal evolution on the strength of BSM dominant covariation mode in different categories.

Generally, the SEN experiments could validate the SSTAs' effects on the phase relationship of rainfall IAV between the WNP and NAM regions. When the warm SSTA centered near the MC is added in the SEN_S1 experiment (Fig. 8b), the stronger local ascending occurs to suppress the WNP rainfall by inducing an abnormal descending to its north (Figs. 13a,c), while the anomalies of zonally adjusted circulation are obtained, along with the ascending branch over the tropical western and eastern Pacific, respectively (Fig. 13b). Thus, the NAM rainfall becomes abundant in summer, especially over the southern NAM region (Fig. 13a). The SEN_S2 experiment, in which the cold SSTA is significant in the equatorial central-eastern Pacific in summer (Fig. 9b), is able to reproduce the abnormal ascending over the WNP and descending over the NAM region, respectively (Figs. 13e,f). Thus, greater and less than normal rainfall are respectively obtained over the WNP and central-eastern NAM (Fig. 13d). As for the SEN W1 experiment forced by the evident warmer SSTA in the TIO (Fig. 10b), the strengthened ascent is sinking over both the WNP and NAM (Fig. 13h), and the abnormal meridional descending over the WNP can be well simulated in this experiment (Fig. 13i), leading to the in-phase weakening of WNP and NAM monsoon rainfall (Fig. 13g). In the SEN_W2 experiment forced by the cold SSTA in TIO and equatorial central-eastern Pacific and the warm SSTA in the WNP (Fig. 11b), the anomalous ascending and low-level convergence over the WNP area are captured (Fig. 13k), along with the greater than normal summer rainfall in situ (Fig. 13j). In the meantime, the ascending anomaly exists over the NAM, which is associated with the strong abnormal descending over the colder equatorial central-eastern Pacific (Fig. 131). Then the convection gets enhanced over both the WNP and the western NAM regions in the SEN_W2 experiment (Fig. 13j). Although the circulation 
(a) Prec.

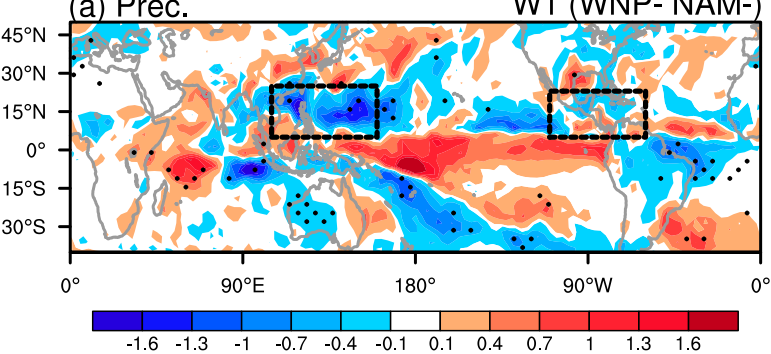

(c) Zonal Circul. \& Q1

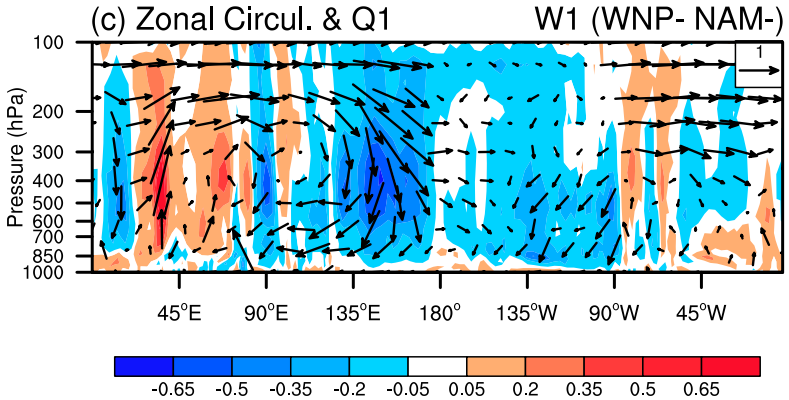

(b) SST \& HGT $925 \mathrm{hPa}$

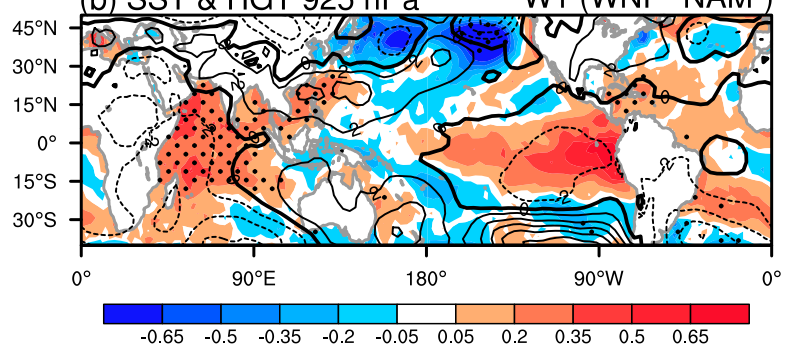

(d) Meridional Circul. \& Q1

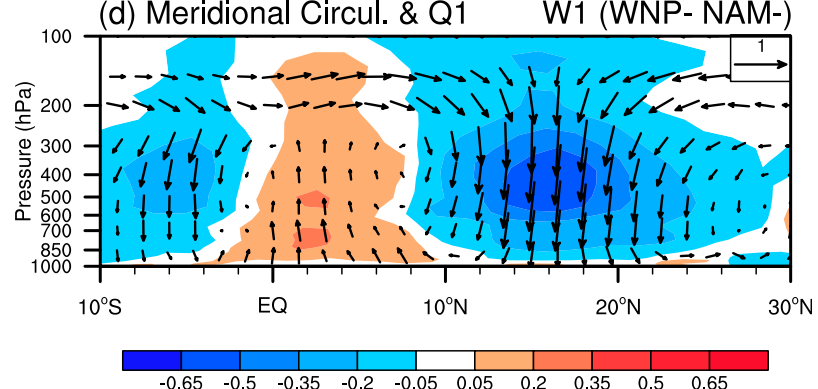

FIG. 10. Composite MJJAS (a) precipitation (shading interval $0.3 \mathrm{~mm} \mathrm{day}^{-1}$ ), (b) SST (shading interval $0.15^{\circ} \mathrm{C}$ ) and geopotential height (contour interval $3 \mathrm{~m}$ ) at $925 \mathrm{hPa}$, (c) $5^{\circ}-20^{\circ} \mathrm{N}$ averaged pressure-longitudinal cross section of zonal circulation, and (d) $105^{\circ}-155^{\circ} \mathrm{E}$ averaged pressure-latitudinal cross section of meridional circulation over the WNP monsoon region in W1 category. Solid (dashed) lines in (b) denote positive (negative) values. The composite precipitation and SST exceeding $90 \%$ confidence level in (a) and (b) are stippled in black. Black dashed lines denote approximate WNP and NAM monsoon domains.

anomalies associated with the SSTA forcing are reproduced in the SEN experiments, the response of rainfall anomalies is not completely consistent with the observation, especially over the NAM region. It is possible ascribed to the microphysical process and the convection parameterization in the CAM5.1 model (Gervais et al. 2014; Bacmeister et al. 2014).

\section{Summaries and discussion}

\section{a. Summaries}

The IAV of monsoon rainfall has been a concern for more than half a century. The seasonal prediction of BSM rainfall is a great challenge, and the current dynamical models show moderate skill scores in the GM regions (Wang et al. 2009; Saha et al. 2016). Many previous studies have paid attention to the IAV of regional summer monsoon rainfall, especially over the BSM region, where the climate variability is very sensitive to the monsoon activity. In the present, we focused on the covariation among the BSM members including the WNP, IND, EA, NAM, and NAF monsoon rainfall on the interannual time scale, investigating the features of the BSM dominant covariation mode and the possible mechanism for its maintain and interannual changes. Since the BSM dominant covariation mode is closely associated with the preceding slow-varying tropical
SSTAs in the eastern Pacific on an interannual time scale, it can be treated as an alternative predictand for the rainfall IAV over the BSM domain. This mode also provides a potential benchmark to verify the model performance on the seasonal prediction of BSM rainfall. The major conclusions are summarized as follows.

1) The BSM dominant covariation mode is defined by the first EOF leading mode of the rainfall IAV over the five BSM subregions, and the strength of this mode can be measured by its principal component (PC1). In the positive phase of this mode, the WNP rainfall is suppressed, along with the enhanced convection over the other four BSM subregions. Both statistical and LBM analysis suggest that the interaction of rainfall IAV between the WNP and NAM is critical to the maintaining and variation of this mode. In particular, the abnormal atmospheric circulation associated with this mode features the anomalies of zonally coupled circulation over the tropical oceans, with its descending branch located over the tropical Pacific and the ascending one over the TIO and NAM regions. These two zonal circulations link the WNP, IND, and NAM monsoon systems. Meanwhile, a meridional circulation anomaly with its descending branch over the WNP and its ascending branch over southern EA is able to connect the WNP and EA summer monsoon 
(a) Prec

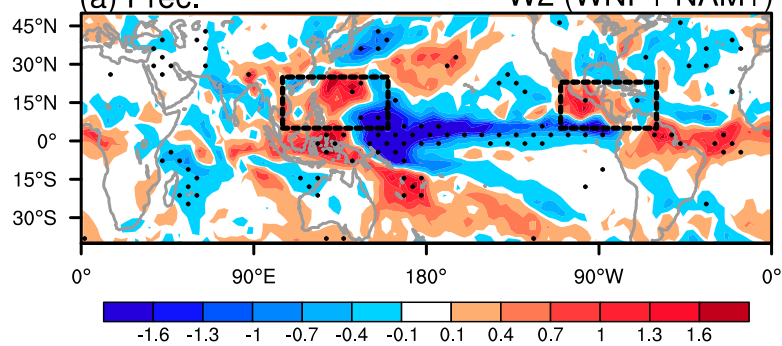

(c) Zonal Circul. \& Q1

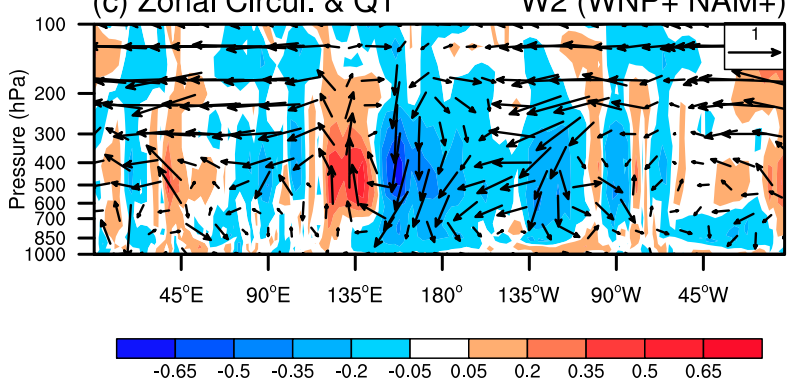

(b) SST \& HGT $925 \mathrm{hPa}$

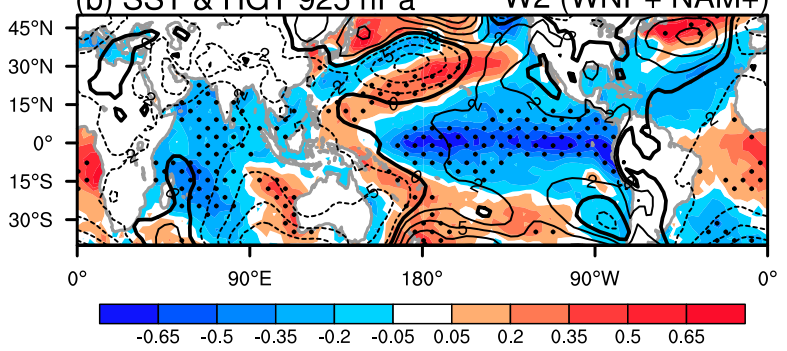

(d) Meridional Circul. \& Q1 W2 (WNP+ NAM+)

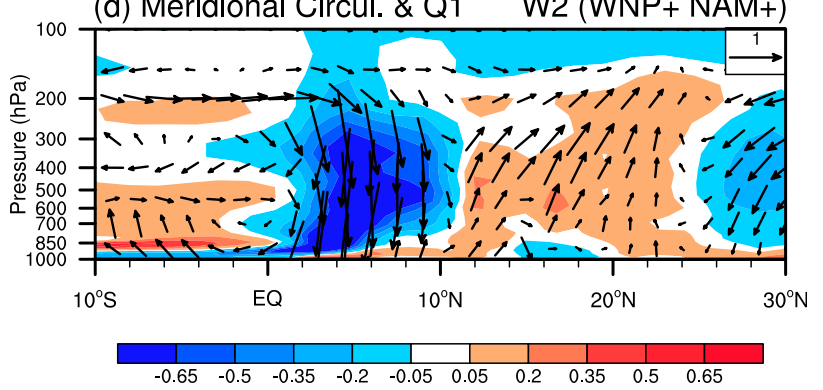

FIG. 11. Composite MJJAS (a) precipitation (shading interval $0.3 \mathrm{~mm} \mathrm{day}^{-1}$ ), (b) SST (shading interval $0.15^{\circ} \mathrm{C}$ ) and geopotential height (contour interval $3 \mathrm{~m}$ ) at $925 \mathrm{hPa}$, (c) $5^{\circ}-20^{\circ} \mathrm{N}$ averaged pressure-longitudinal cross section of zonal circulation, and $(\mathrm{d}) 100^{\circ}-80^{\circ} \mathrm{W}$ averaged pressure-latitudinal cross section of meridional circulation over the NAM monsoon region in the W2 category. Solid (dashed) lines in (b) denote positive (negative) values. The composite precipitation and SST exceeding 90\% confidence level in (a) and (b) are stippled in black. Black dashed lines denote approximate WNP and NAM monsoon domains.

rainfall. In this mode, the WNP and the NAM monsoon rainfall are affected by the remarkable upper- and lower-level circulation anomalies with evident vertical coupling, whereas the upper- and lower-level circulations regulate the monsoon rainfall over the NAF and the IND, respectively. The positive (negative) phase of this mode is controlled by the warm (cold) ENSO events in the previous winter.

2) Except for its phase transition, the strength of the BSM dominant covariation mode is modulated by the phase relationship of summer rainfall IAV between the WNP and NAM regions, which is ascribed to the temporal evolution of ENSOrelated SSTAs in the tropical Indian and Pacific Ocean during the preceding seasons. When this mode is strong, the rainfall IAV between the WNP and NAM is out of phase, corresponding to the fast decaying of the ENSO event and the resultant tropical SSTAs from winter to summer. In this case, the ENSO-related "atmospheric bridge" effect is limited, and the TIO SSTA becomes weaker. However, when this mode is weak, along with the inphase rainfall IAV between the WNP and NAM regions, the ENSO event persists in boreal spring and summer, leading to a stronger SSTA in the TIO under the influence of the enhanced atmospheric bridge. The anomalies of zonal and meridional circulation associated with the distinct seasonal evolution of ENSO events can be reproduced by a series of AGCM sensitivity experiments, suggesting that the phase and strength of the BSM dominant covariation mode depend on the external SSTA forcing in the tropics.

\section{b. Discussion}

For validating the effects of ENSO evolution on the strength of dominant BSM covariation mode, we have examined some extreme cases in the specific years. For instance, the fast decaying El Niño in 2009/10 is followed by the strongest mode with its positive phase, whereas the strongest mode in the negative phase occurs after the rapidly fading La Niña in 2008/09 (Figs. 12a,b). Thus, the effects of ENSO on the dominant BSM covariation mode are valid for most cases. However, some exceptions still exist, especially in the S1 and W2 categories when the NAM monsoon convection is stronger. In particular, the negative PC1 in 1980, 1982, 2004, and 2014 is opposite to the composite results of the S1 category, whereas the PC1 in 1988 and 2002 is larger than one STD, inconsistent with the weaker mode in the W2 category (Fig. 7b). Note that most of these exceptions are non-ENSO years $(1982,2004$, and 2014 in the S1; 
(a) Nino 3.4 index

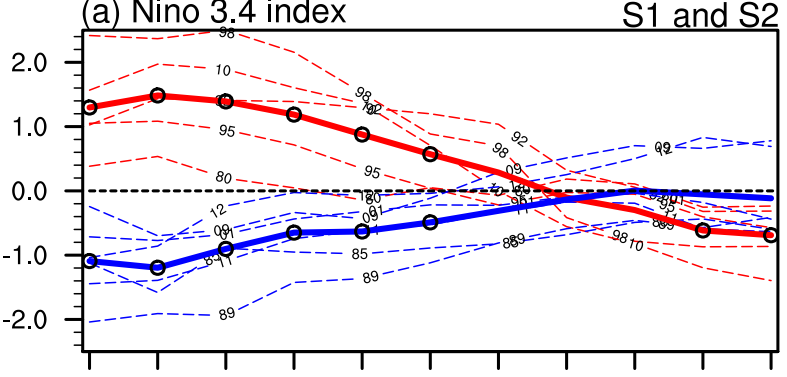

(c) TIO index

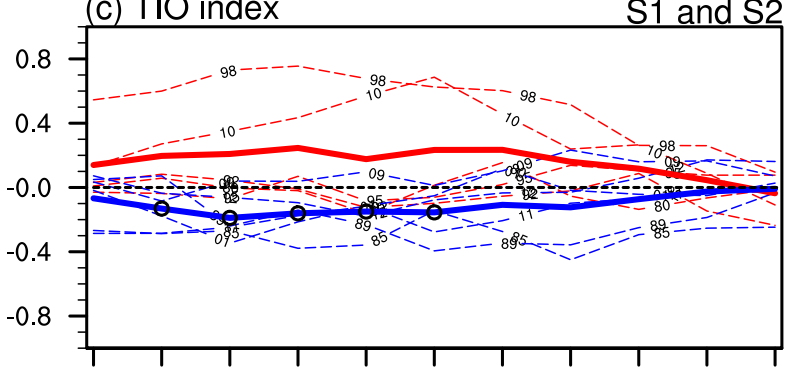

(e) Lagged Corr.

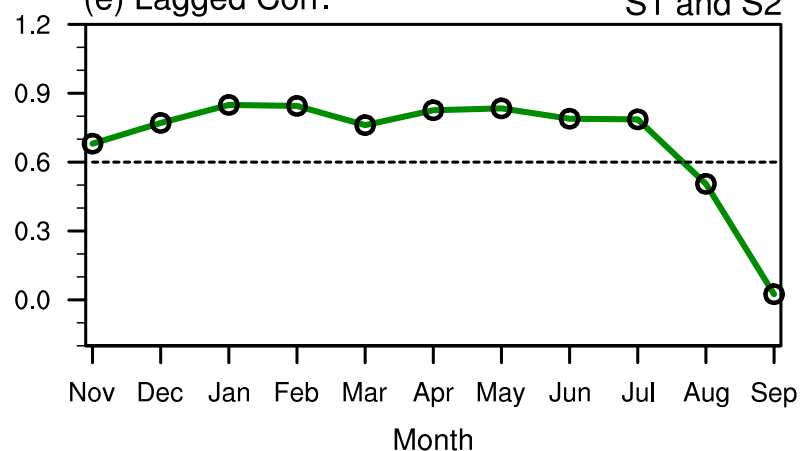

(b) Nino 3.4 index

$\mathrm{W} 1$ and $\mathrm{W} 2$

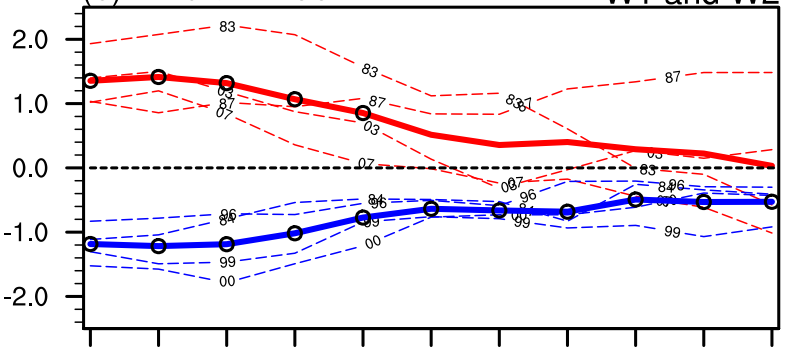

(d) TIO index

$\mathrm{W} 1$ and $\mathrm{W} 2$

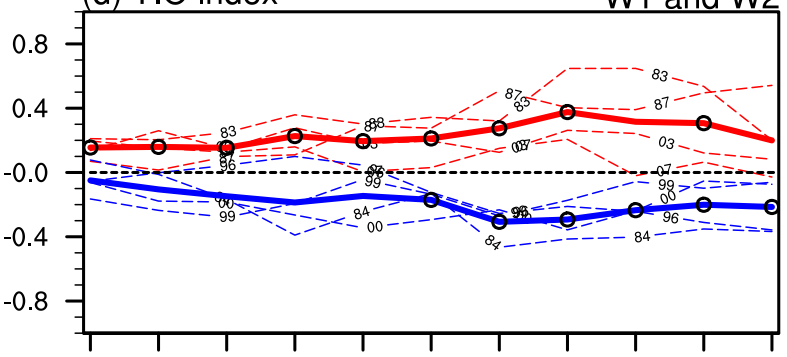

(f) Lagged Corr.

W1 and W2

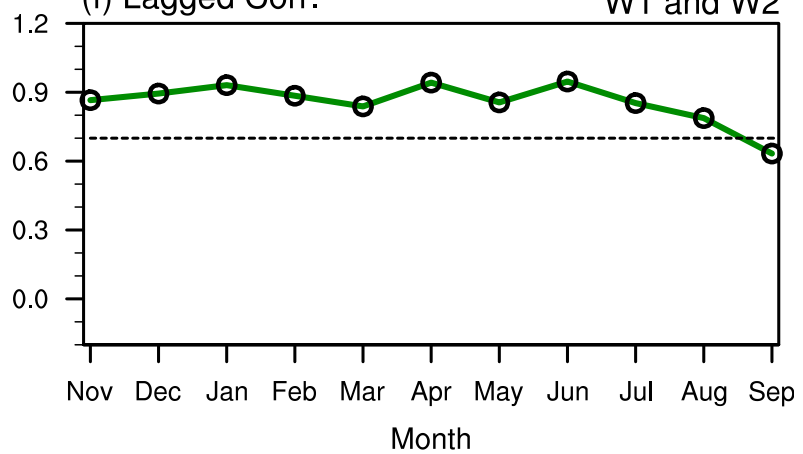

FIG. 12. Temporal evolutions of the composite (a),(b) Niño-3.4 index and (c),(d) TIO index, as well as the (e),(f) lagged correlation between the Niño 3.4 in winter (November-January) and the TIO index in the subsequent months in four categories: (left) strong mode categories (S1 in red, and S2 in blue) of the BSM covariation mode and (right) weak mode categories (W1 in red, and W2 in blue). Solid lines illustrate their corresponding group averaged evolutions. The composite values exceeding $95 \%$ confidence level are circled in black.

2002 in the W2), implicating possible non-ENSO influences (e.g., Saha et al. 2016) on the BSM dominant covariation mode, which requires further investigation in the future.

However, the present conclusions are available for the interdecadal variation of the dominant BSM mode. The IAV of rainfall has become weaker over the BSM domain since the early 1990s (e.g., Zhou et al. 2008; Lee et al. 2014), indicating less seasonal predictability for individual BSM members. However, the BSM dominant covariation mode gets enhanced after the early 1990s, with STD values of 0.62 and 0.85 before and after 1994, respectively. A similar decadal adjustment of BSM rainfall variation has been reported by Lee et al. (2014).
In the meantime, the Atlantic multidecadal oscillation (AMO) enters its warm phase from the cold one after 1994 (Trenberth and Shea 2006; Wang and Zhang 2013), corresponding to the faster decaying ENSO events and the stronger PC1 variation during 1995-2014 (figure not shown). Thus, the decaying speed of ENSO could even modulate the intensity of the BSM dominant covariation mode on the decadal time scale related to the AMO transition in early 1990s.

In the decaying of ENSO events, another teleconnection pattern in the upper troposphere named the western Pacific-North America (WPNA) pattern has been proposed to link the WNP convection and the extratropical circulation in boreal summer (Ding et al. 

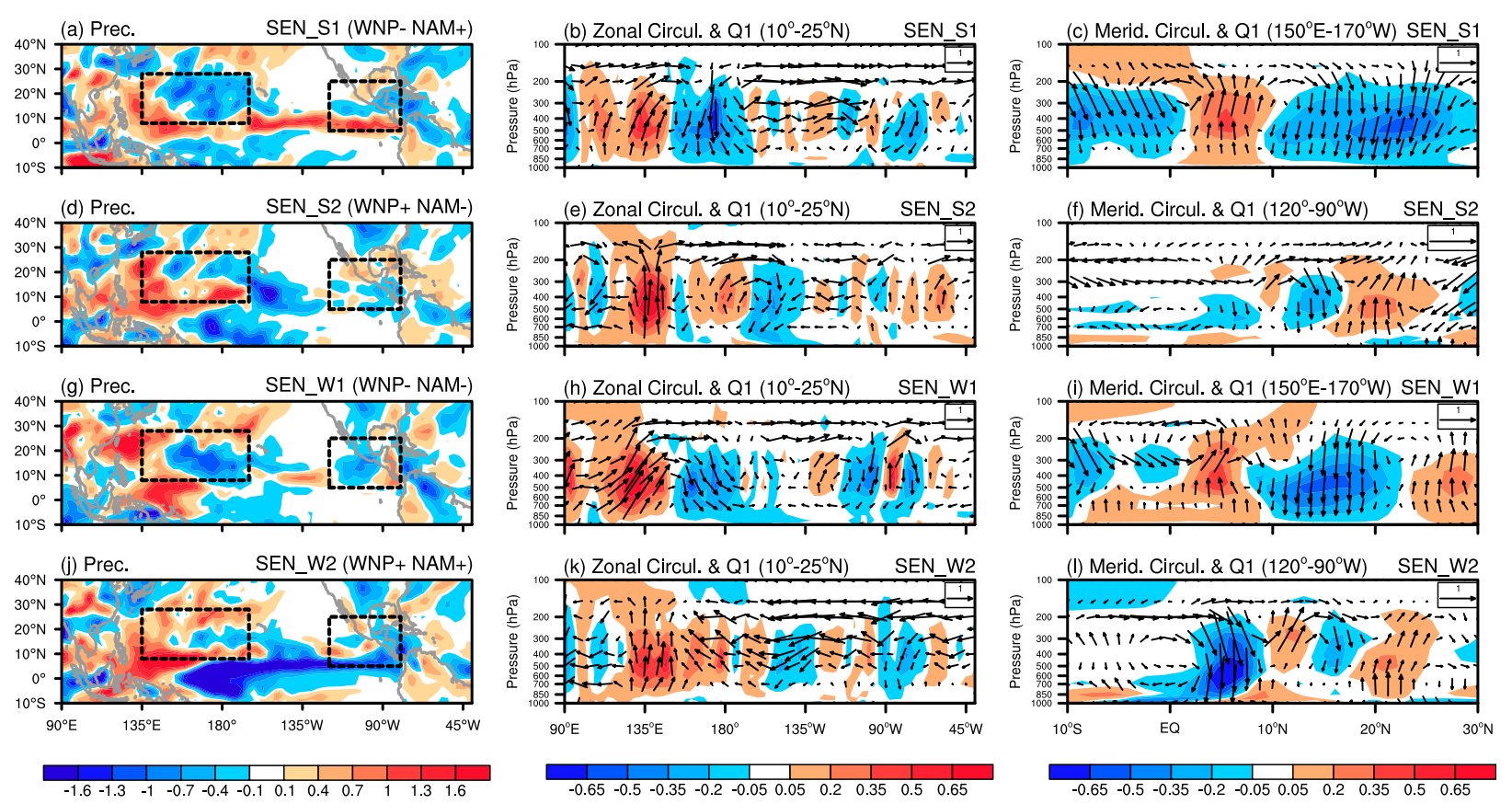

FIG. 13. Differences of (left) precipitation $\left(\mathrm{mm} \mathrm{day}^{-1}\right)$, (middle) zonal (vectors; $\mathrm{m} \mathrm{s}^{-1}$ ), and (right) meridional circulations (vectors; $\mathrm{m} \mathrm{s}^{-1}$ ) in the four sensitivity experiments [(a)-(c) SEN_S1, (d)-(f) SEN_S2, (g)-(i) SEN_W1, and (j)-(1) SEN_W2] compared with the CTL runs (SEN minus CTL) in the CAM5.1 model. The shadings in the middle and right column represent the differences of $Q_{1}\left(\mathrm{~K} \mathrm{day}^{-1}\right)$. In the middle column, the pressure-longitudinal cross section is averaged along $10^{\circ}-25^{\circ} \mathrm{N}$. The $150^{\circ} \mathrm{E}-170^{\circ} \mathrm{W}$ averaged pressure-latitudinal cross section of abnormal winds and $Q_{1}$ over the WNP region are provided in (c) and (i), whereas the counterparts across the NAM region (averaged along $120^{\circ}-90^{\circ} \mathrm{W}$ ) are shown in (f) and (l). Black dashed lines denote the approximate WNP and NAM monsoon domains in the CTL runs.

2011; Lee and Ha 2015; Ha et al. 2018). However, the WPNA pattern shows little influence on the BSM dominant covariation mode. Although the tropical SSTA related to the PC1 could produce an upper-level hemispheric uniform pattern favoring the formation of the WPNA pattern, the extratropical wave pattern induced by the WNP convection is altered by the Rossby wave response of circulation to the NAM summer monsoon, as suggested by the LBM experiment (figures not shown). Therefore, one cannot observe the WPNA pattern in the PC1-regressed geopotential height field. In addition, we have checked the behavior of the WPNA pattern in the four categories identified by different interrelation between the WNP and NAM monsoon. But none of them exhibits a well-organized WPNA pattern with statistical significance. The lack of WPNA pattern is indicative of that the dominant BSM covariation mode is distinct from the global effects of the WNP monsoon, even though they are closely associated with each other.

Except for the first EOF mode, we have noticed that the second EOF mode of the rainfall IAV over the BSM domain (named the second mode hereafter) with the distinct characteristics is stronger before 1994. In the second mode, with an explained variance of $9.8 \%$, the rainfall IAV over the EA in the subtropics is out of phase with that over the other BSM subregions in the tropics (figure not shown). The STD of its principal component (PC2) is 0.95 and 0.65 before and after 1994 during 1979-2014. The PC2 is correlated with the developing ENSO-like SSTAs in the previous seasons (figure not shown), during which the circumglobal teleconnection (CGT) pattern partly due to the intrinsic mode of the midlatitudinal circulation may come out to link the tropical and extratropical monsoon systems (Ding et al. 2011). Thus, we speculate that the second mode may be more dependent on the internal association among the BSM members. Of course, more details about the second mode, including its related circulation, maintenance mechanisms, and contributions from the internal and external factors, need further investigation in the future.

Acknowledgments. This work was jointly supported by the National Science Foundation of China (41475057, 41775052, 91537103, 91637312), the Basic Scientific Research and Operation Foundation of the CAMS under Grants 2015Z001 and 2017R001, and the Special Funds for Central Government Guiding Development of Local Science \& Technology (ZY18C12). 


\section{REFERENCES}

Adams, J. L., and D. J. Stensrud, 2007: Impact of tropical easterly waves on the North American monsoon. J. Climate, 20,1219-1238, https://doi.org/10.1175/JCLI4071.1.

Adler, R. F., and Coauthors, 2003: The version-2 Global Precipitation Climatology Project (GPCP) monthly precipitation analysis (1979-present). J. Hydrometeor., 4, 1147-1167, https:// doi.org/10.1175/1525-7541(2003)004<1147:TVGPCP >2.0.CO;2.

Alexander, M. A., I. Bladé, M. Newman, J. R. Lanzante, N. C. Lau, and J. D. Scott, 2002: The atmospheric bridge: The influence of ENSO teleconnections on air-sea interaction over the global oceans. J. Climate, 15, 2205-2231, https://doi.org/ 10.1175/1520-0442(2002)015<2205:TABTIO > 2.0.CO;2.

An, Z. S., and Coauthors, 2015: Global monsoon dynamics and climate change. Annu. Rev. Earth Planet. Sci., 43, 29-77, https://doi.org/10.1146/annurev-earth-060313-054623.

Annamalai, H., S. Kida, and J. Hafner, 2010: Potential impact of the tropical Indian Ocean-Indonesian Seas on El Niño characteristics. J. Climate, 23, 3933-3952, https://doi.org/10.1175/ 2010JCLI3396.1.

Bacmeister, J. T., M. F. Wehner, R. B. Neale, A. Gettelman, C. Hannay, P. H. Lauritzen, J. M. Caron, and J. E. Truesdale, 2014: Exploratory high-resolution climate simulations using the Community Atmosphere Model (CAM). J. Climate, 27, 3073-3099, https://doi.org/10.1175/JCLI-D-13-00387.1.

Barlow, M., and D. Salstein, 2006: Summertime influence of the Madden-Julian Oscillation on daily rainfall over Mexico and Central America. Geophys. Res. Lett., 33, L21708, https://doi.org/ 10.1029/2006GL027738.

Boos, W. R., and J. V. Hurley, 2013: Thermodynamic bias in the multimodel mean boreal summer monsoon. J. Climate, 26, 2279-2287, https://doi.org/10.1175/JCLI-D-12-00493.1.

Castro, C. L., T. B. McKee, and R. A. Pielke Sr., 2001: The relationship of the North American monsoon to tropical and North Pacific sea surface temperatures as revealed by observational analyses. J. Climate, 14, 4449-4473, https:// doi.org/10.1175/1520-0442(2001)014<4449:TROTNA >2.0.CO;2.

Dee, D. P., and Coauthors, 2011: The ERA-Interim reanalysis: Configuration and performance of the data assimilation system. Quart. J. Roy. Meteor. Soc., 137, 553-597, https://doi.org/ 10.1002/qj.828.

Ding, Q. H., B. Wang, J. M. Wallace, and G. Branstator, 2011: Tropical-extratropical teleconnections in boreal summer: Observed interannual variability. J. Climate, 24, 1878-1896, https://doi.org/10.1175/2011JCLI3621.1.

Ding, R. Q., K. Ha, and J. P. Li, 2010: Interdecadal shift in the relationship between the East Asian summer monsoon and the tropical Indian Ocean. Climate Dyn., 34, 1059-1071, https://doi.org/10.1007/s00382-009-0555-2.

Ding, Y. H., and J. C. L. Chan, 2005: The East Asian summer monsoon: An overview. Meteor. Atmos. Phys., 89, 117-142, https://doi.org/10.1007/s00703-005-0125-z.

Gervais, M., J. R. Gyakum, E. Atallah, and L. B. Tremblay, 2014: How well are the distribution and extreme values of daily precipitation over North America represented in the Community Climate System Model? A comparison to reanalysis, satellite, and gridded station data. J. Climate, 27, 5219-5239, https://doi.org/10.1175/JCLI-D-13-00320.1.

Goswami, B. N., and R. S. A. Mohan, 2001: Intraseasonal oscillations and interannual variability of the Indian summer monsoon. J. Climate, 14, 1180-1198, https://doi.org/10.1175/ 1520-0442(2001)014<1180:IOAIVO>2.0.CO;2.
Gutzler, D. S., and J. W. Preston, 1997: Evidence for a relationship between spring snow cover in North American and summer rainfall in New Mexico. Geophys. Res. Lett., 24, 2207-2210, https://doi.org/10.1029/97GL02099.

Ha, K.-J., Y.-W. Seo, J.-Y. Lee, R. H. Kripalani, and K.-S. Yun, 2018: Linkages between the South and East Asian summer monsoons: A review and revisit. Climate Dyn., https://doi.org/ 10.1007/s00382-017-3773-z, in press.

Hao, Y.-Q., C.-W. Zhu, and B.-Q. Liu, 2016: Discrepancies in boreal summer monsoon rainfall between GPCP and CMAP products during 1979-2014. Atmos. Ocean. Sci. Lett., 9, 226-233, https://doi.org/10.1080/16742834.2016.1168603.

Hawkins, T. W., A. W. Ellis, J. A. Skindlov, and D. Reigle, 2002: Intraannual analysis of the North American snow cover-monsoon teleconnection: Seasonal forecasting utility. J. Climate, 15, 1743-1753, https://doi.org/10.1175/1520-0442(2002)015<1743: IAAOTN $>2.0 . \mathrm{CO} ; 2$.

Hsu, P., T. Li, and B. Wang, 2011: Trends in global monsoon area and precipitation over the past 30 years. Geophys. Res. Lett., 38, L08701, https://doi.org/10.1029/2011GL046893.

Huang, B., 2004: Remotely forced variability in the tropical Atlantic Ocean. Climate Dyn., 23, 133-152, https://doi.org/ 10.1007/s00382-004-0443-8.

Huang, G., K. Hu, and S.-P. Xie, 2010: Strengthening of tropical Indian Ocean teleconnection to the northwest Pacific since the mid-1970s: An atmospheric GCM study. J. Climate, 23, 52945304, https://doi.org/10.1175/2010JCLI3577.1.

, X. Qu, and K. Hu, 2011: The impact of the tropical Indian Ocean on South Asian high in boreal summer. Adv. Atmos. Sci., 28, 421-432, https://doi.org/10.1007/s00376-010-9224-y.

Huffman, G. J., and Coauthors, 1997: The Global Precipitation Climatology Project (GPCP) combined precipitation dataset. Bull. Amer. Meteor. Soc., 78, 5-20, https://doi.org/10.1175/ 1520-0477(1997)078<0005:TGPCPG >2.0.CO;2.

Klein, S. A., B. J. Soden, and N. C. Lau, 1999: Remote sea surface temperature variations during ENSO: Evidence for a tropical atmospheric bridge. J. Climate, 12, 917-932, https://doi.org/ 10.1175/1520-0442(1999)012<0917:RSSTVD > 2.0.CO;2.

Koster, R. D., and Coauthors, 2004: Regions of strong coupling between soil moisture and precipitation. Science, 305, 11381140, https://doi.org/10.1126/science.1100217.

Kumar, K. K., B. Rajagopalan, and M. A. Cane, 1999: On the weakening relationship between the Indian monsoon and ENSO. Science, 284, 2156-2159, https://doi.org/10.1126/ science.284.5423.2156.

Lau, K.-M., and H. Y. Weng, 2002: Recurrent teleconnection patterns linking summertime precipitation variability over East Asia and North America. J. Meteor. Soc. Japan, 80, 13091324, https://doi.org/10.2151/jmsj.80.1309.

Lee, E.-J., K.-J. Ha, and J.-G. Jhun, 2014: Interdecadal changes in interannual variability of the global monsoon precipitation and interrelationships among its subcomponents. Climate Dyn., 42, 2585-2601, https://doi.org/10.1007/s00382-013-1762-4.

Lee, J.-Y., and K.-J. Ha, 2015: Understanding of interdecadal changes in variability and predictability of the Northern Hemisphere summer tropical-extratropical teleconnection. J. Climate, 28, 8634-8647, https://doi.org/10.1175/ JCLI-D-15-0154.1.

Li, J. P., and Q. C. Zeng, 2002: A unified monsoon index. Geophys. Res. Lett., 29, 1274, https://doi.org/10.1029/2001GL013874. , and - 2003: A new monsoon index and the geographical distribution of the global monsoons. Adv. Atmos. Sci., 20, 299302, https://doi.org/10.1007/s00376-003-0016-5. 
Li, T., B. Wang, and L. Wang, 2016: Comments on "Combination mode dynamics of the anomalous northwest Pacific anticyclone." J. Climate, 29, 4685-4693, https://doi.org/10.1175/ JCLI-D-15-0385.1.

Linderholm, H. W., T. Ou, J.-H. Jeong, C. K. Folland, D. Gong, H. Liu, Y. Liu, and D. Chen, 2011: Interannual teleconnections between the summer North Atlantic Oscillation and the East Asian summer monsoon. J. Geophys. Res., 116, D13107, https://doi.org/10.1029/2010JD015235.

Liu, Y. M., G. X. Wu, H. Liu, and P. Liu, 2001: Condensation heating of the Asian summer monsoon and the subtropical anticyclone in the Eastern Hemisphere. Climate Dyn., 17, 327338, https://doi.org/10.1007/s003820000117.

Liu, Y. Y., and Y. H. Ding, 2008: Teleconnection between the Indian summer monsoon onset and the Meiyu over the Yangtze River Valley. Sci. China, 51D, 1021-1035, https://doi.org/ 10.1007/s11430-008-0073-9.

Lorenz, D. J., and D. L. Hartmann, 2006: The effect of the MJO on the North American monsoon. J. Climate, 19, 333-343, https:// doi.org/10.1175/JCLI3684.1.

Ma, H., Z. Jiang, J. Song, A. Dai, X. Yang, and F. Huo, 2016: Effects of urban land-use change in East China on the East Asian summer monsoon based on the CAM5.1 model. Climate Dyn., 46, 2977-2989, https://doi.org/10.1007/s00382-015-2745-4.

Pan, L.-L., F.-F. Jin, and M. Watanabe, 2006: Dynamics of synoptic eddy and low-frequency flow interaction. Part III: Baroclinic model results. J. Atmos. Sci., 63, 1709-1725, https://doi.org/ 10.1175/JAS3717.1.

Pang, Y. S., C. W. Zhu, and K. Liu, 2014: Analysis of stability of EOF modes in summer rainfall anomalies in China (in Chinese). Chin. J. Atmos. Sci., 38, 1137-1146.

Qian, W. H., 2000: Dry/wet alternation and global monsoon. Geophys. Res. Lett., 27, 3679-3682, https://doi.org/10.1029/ 1999GL011255.

— and global atmospheric centers of action on a pentad scale. Atmos. Ocean. Sci. Lett., 3, 1-6, https://doi.org/10.1080/ 16742834.2010.11446841.

Quadrelli, R., C. S. Bretherton, and J. M. Wallace, 2005: On sampling errors in empirical orthogonal functions. J. Climate, $\mathbf{1 8}$, 3704-3710, https://doi.org/10.1175/JCLI3500.1.

Raicich, F., N. Pinardi, and A. Navarra, 2003: Teleconnections between Indian monsoon and Sahel rainfall and the Mediterranean. Int. J. Climatol., 23, 173-186, https://doi.org/10.1002/joc.862.

Rayner, N. A., P. Brohan, D. E. Parker, C. K. Folland, J. J. Kennedy, M. Vanicek, T. J. Ansell, and S. F. B. Tett, 2006: Improved analyses of changes and uncertainties in sea surface temperature measured in situ since the mid-nineteenth century: The HadSST2 dataset. J. Climate, 19, 446-469, https:// doi.org/10.1175/JCLI3637.1.

Reyes, S., and D. L. Cadet, 1988: The southwest branch of the North American monsoon during 1979. Mon. Wea. Rev., 116, 1175-1187, https://doi.org/10.1175/1520-0493(1988)116<1175: TSBOTN $>2.0 . \mathrm{CO} ; 2$.

— eastern Pacific and the precipitation field over north-western Mexico in relation to the ENSO phenomenon. Int. J. Climatol., 11, 515-528, https://doi.org/10.1002/joc.3370110505.

Rodwell, M. J., and B. J. Hoskins, 1996: Monsoons and the dynamics of deserts. Quart. J. Roy. Meteor. Soc., 122, 1385-1404, https://doi.org/10.1002/qj.49712253408.

Rowell, D. P., C. K. Folland, K. Maskell, and M. N. Ward, 1995: Variability of summer rainfall over tropical North Africa
(1906-92): Observations and modelling. Quart. J. Roy. Meteor. Soc., 121, 669-704, https://doi.org/10.1002/qj.49712152311.

Saha, S. K., K. Sujith, S. Pokhrel, H. S. Chaudhari, and A. Hazra, 2016: Predictability of global monsoon rainfall in NCEP CFSv2. Climate Dyn., 47, 1693-1715, https://doi.org/10.1007/ s00382-015-2928-z.

Tan, Y. K., J. H. He, and C. W. Zhu, 1999: Impact of Eurasian winter snow cover on the Northern Hemisphere summer circulation and its possible relation to East Asia Pacific teleconnection pattern (in Chinese). Chin. J. Atmos. Sci., 23, 152-160.

Trenberth, K. E., and D. J. Shea, 2006: Atlantic hurricanes and natural variability in 2005. Geophys. Res. Lett., 33, L12704, https://doi.org/10.1029/2006GL026894.

_ D. D. P. Stepaniak, and J. M. Caron, 2000: The global monsoon as seen through the divergent atmospheric circulation. J. Climate, 13, 3969-3993, https://doi.org/10.1175/1520-0442(2000)013<3969: TGMAST $>2.0 . \mathrm{CO} ; 2$.

Vinoj, V., P. J. Rasch, H. Wang, J.-H. Yoon, P.-L. Ma, K. Landu, and B. Singh, 2014: Short-term modulation of Indian summer monsoon rainfall by West Asian dust. Nat. Geosci., 7, 308-313, https://doi.org/10.1038/ngeo2107.

Wang, B., 1994: Climatic regimes of tropical convection and rainfall. J. Climate, 7, 1109-1118, https://doi.org/10.1175/ 1520-0442(1994)007<1109:CROTCA > 2.0.CO;2.

— , and Q. Ding, 2006: Changes in global monsoon precipitation over the past 56 years. Geophys. Res. Lett., 33, L06711, https:// doi.org/10.1029/2005GL025347.

— variation in the tropics. Dyn. Atmos. Oceans, 44, 165-183, https://doi.org/10.1016/j.dynatmoce.2007.05.002.

— R. G. Wu, and X. H. Fu, 2000: Pacific-East Asian teleconnection: How does ENSO affect East Asian climate? J. Climate, 13, 1517-1536, https://doi.org/10.1175/15200442(2000)013<1517:PEATHD > 2.0.CO;2.

$\longrightarrow$, _ - and K.-M. Lau, 2001: Interannual variability of the Asian summer monsoon: Contrasts between the Indian and the western North Pacific-East Asian monsoons. J. Climate, 14, 4073-4090, https://doi.org/10.1175/1520-0442(2001)014<4073: IVOTAS $>2.0 . \mathrm{CO} ; 2$.

—_ — - and T. Li, 2003: Atmosphere-warm ocean interaction and its impact on Asian-Australian monsoon variability: Strengthening relationship with ENSO since the late 1970s. J. Climate, 16, 1195-1211, https://doi.org/ 10.1175/1520-0442(2003)16<1195:AOIAII > 2.0.CO;2.

, and Coauthors, 2009: Advance and prospectus of seasonal prediction: Assessment of the APCC/CliPAS 14-model ensemble retrospective seasonal prediction (1980-2004). Climate Dyn., 33, 93-117, https://doi.org/ 10.1007/s00382-008-0460-0.

—_ J. Liu, H.-J. Kim, P. J. Webster, and S.-Y. Yim, 2012: Recent change of the global monsoon precipitation (19792008). Climate Dyn., 39, 1123-1135, https://doi.org/10.1007/ s00382-011-1266-Z.

Wang, C., and L. Zhang, 2013: Multidecadal ocean temperature and salinity variability in the tropical North Atlantic: Linking with the AMO, AMOC, and subtropical cell. J. Climate, 26, 6137-6162, https://doi.org/10.1175/JCLI-D-12-00721.1.

Watanabe, M., and M. Kimoto, 2000: Atmosphere-ocean thermal coupling in the North Atlantic: A positive feedback. Quart. J. Roy. Meteor. Soc., 126, 3343-3369, https://doi.org/10.1002/ qj.49712657017.

Webster, P. J., 1987: The elementary monsoon. Monsoons, J. S. Fein and P. L. Stephens, Eds., Wiley, 3-32. 
- and S. Yang, 1992: Monsoon and ENSO: Selectively interactive systems. Quart. J. Roy. Meteor. Soc., 118, 877-926, https://doi.org/10.1002/qj.49711850705.

__ , and J. Fasullo, 2003: Monsoon: Dynamical theory. Encyclopedia of Atmospheric Sciences, Vol. 3, J. R. Holton, J. A. Curry, and J. A. Pyle, Eds., Academic Press, 1370-1391.

Wu, B., T. Zhou, and T. Li, 2009: Seasonal evolving dominant interannual variability modes of East Asian climate? J. Climate, 22, 2992-3005, https://doi.org/10.1175/ 2008JCLI2710.1.

Wu, R. G., and B. Wang, 2000: Interannual variability of summer monsoon onset over the western North Pacific and the underlying processes. J. Climate, 13, 2483-2501, https://doi.org/ 10.1175/1520-0442(2000)013<2483:IVOSMO > 2.0.CO;2.

Xie, P., and P. A. Arkin, 1997: Global precipitation: A 17-year monthly analysis based on gauge observations, satellite estimates, and numerical model outputs. Bull. Amer. Meteor. Soc., 78, 2539-2558, https://doi.org/10.1175/1520-0477(1997)078<2539: GPAYMA $>2.0 . \mathrm{CO} ; 2$.

Xie, S.-P., K. Hu, J. Hafner, H. Tokinaga, Y. Du, G. Huang, and T. Sampe, 2009: Indian Ocean capacitor effect on Indowestern Pacific climate during the summer following El Niño. J. Climate, 22, 730-747, https://doi.org/10.1175/ 2008JCLI2544.1.

Yanai, M., S. Esbensen, and J. H. Chu, 1973: Determination of bulk properties of tropical cloud clusters from large-scale heat and moisture budgets. J. Atmos. Sci., 30, 611-627, https://doi.org/ 10.1175/1520-0469(1973)030<0611:DOBPOT>2.0.CO;2.

$\mathrm{Yu}, \mathrm{B}$., and J. M. Wallace, 2000: The principal mode of interannual variability of the North American monsoon system. J. Climate,
13, 2794-2800, https://doi.org/10.1175/1520-0442(2000)013<2794: TPMOIV>2.0.CO;2.

Yu, R., J. Li, Y. Zhang, and H. Chen, 2015: Improvement of rainfall simulation on the steep edge of the Tibetan Plateau by using a finite-difference transport scheme in CAM5. Climate Dyn., 45, 2937-2948, https://doi.org/10.1007/s00382-015-2515-3.

Zeng, X., and E. Lu, 2004: Globally unified monsoon onset and retreat indexes. J. Climate, 17, 2241-2248, https://doi.org/ 10.1175/1520-0442(2004)017<2241:GUMOAR>2.0.CO;2.

Zhang, R. H., A. Sumi, and M. Kimoto, 1999: A diagnostic study of the impact of El Niño on the precipitation in China. $A d v$. Atmos. Sci., 16, 229-241, https://doi.org/10.1007/BF02973084.

Zhang, S. P., and B. Wang, 2008: Global summer monsoon rainy seasons. Int. J. Climatol., 28, 1563-1578, https://doi.org/ 10.1002/joc.1659.

Zhao, P., Y. N. Zhu, and R. H. Zhang, 2007: An Asian-Pacific teleconnection in summer tropospheric temperature and associated Asian climate variability. Climate Dyn., 29, 293-303, https://doi.org/10.1007/s00382-007-0236-y.

Zhou, T., R. Yu, H. Li, and B. Wang, 2008: Ocean forcing to changes in global monsoon precipitation over the recent half-century. J. Climate, 21, 3832-3852, https://doi.org/10.1175/2008JCLI2067.1.

, B. Wu, and B. Wang, 2009: How well do atmospheric general circulation models capture the leading modes of the interannual variability of the Asian-Australian monsoon? J. Climate, 22, 1159-1173, https://doi.org/10.1175/2008JCLI2245.1.

Zhu, Z. W., and T. Li, 2016: A new paradigm for continental U.S. summer rainfall variability: Asia-North America teleconnection. J. Climate, 29, 7313-7327, https://doi.org/10.1175/ JCLI-D-16-0137.1. 